\title{
Guineapsaltria, a new genus from the Australian - New Guinean region (Homoptera, Tibicinidae), with notes on its taxonomy and biogeography
}

\author{
A.J. de Boer \\ Institute of Taxonomic Zoology (Zoölogisch Museum), University of Amsterdam, P.O. Box 4766, \\ 1009 AT Amsterdam, The Netherlands
}

Keywords: Guineapsaltria, taxonomy, biogeography, New Guinea, N.E. Australia

\begin{abstract}
The genus Guineapsaltria is erected for eight species, distributed in New Guinea and northeastern Queensland. Five species are transferred from the genus Baeturia Stäl, 1866 and redescribed, viz. G. chinai (Blöte, 1960), G. flava (Goding \& Froggatt, 1904), G. pallida (Blöte, 1960), G. stylata (Blöte, 1960), and G. viridula (Blöte, 1960), while three species are described as new to science (G. flaveola n. sp., G. pallidula n. sp., and $G$. pennyi n. sp.). $G$. flava is designated as the type species of the genus. Baeturia minuta Blöte, 1960 is synonymized with Guineapsaltria flava. The phylogeny of Guineapsaltria is discussed and some remarks are made on its phylogenetic relationships with other New Guinean and Australian tibicinid genera. A key to the males and maps of distribution are presented.
\end{abstract}

\section{Résumé}

Le genre Guineapsaltria est établi pour huit espèces de Nouvelle Guinée et du Queensland du nord-est. Cinq espèces du genre Baeturia Stål sont transférés dans le nouveau genre et redécrites: G. chinai (Blöte, 1960), G. flava (Goding \& Froggatt, 1904), G. pallida (Blöte, 1960), G. stylata (Blöte, 1960) et G. viridula (Blöte, 1960), tandis que trois espèces sont décrites comme nouvelles pour la science ( $G$. flaveola n. sp., G. pallidula n. sp. et G. pennyi n. sp.). G. flava est désignée comme espèce-type du genre. Baeturia minuta Blöte, 1960 est synonymisée avec Guineapsaltria flava. La phylogénie de Guineapsaltria est discutée et des remarques sont faites sur les relations phylétiques avec d'autres genres de Tibicinidae de Nouvelle Guinée et d'Australie. Une clé de détermination pour les mâles est proposée, et des cartes de distribution sont présentées.

\section{Introduction}

The cicada genus Guineapsaltria is erected here to accommodate five species, hitherto included in the genus Baeturia Stål, 1866. These five species are considered to form a monophyletic group, together with three species new to science. A large subapical protrusion on the aedeagus is regarded apomorphous for the genus. The distribution of characters indicates the existence of two clearly monophyletic subgroups, one of four, and one of three species; the phylogenetic position of the remaining species is somewhat uncertain.

Guineapsaltria belongs to the "Baeturia and related genera complex", a supposedly monophyletic group of New Guinean and Australian genera defined earlier on the basis of aedeagal characters (De Boer, 1990). The distribution of this genus complex, with a large number of endemic species in New Guinea and adjacent islands, makes it a promising group for biogeographic and areacladistic studies of this geologically complex region. This publication is intended to form part of such a study.

\section{Material and methods}

The material examined for this study comes from the following institutions:

AMNH American Museum of Natural History, New York

AMS Australian Museum, Sydney

BMNH Natural History Museum (formerly: British Museum (Natural History)), London

BPBM Bernice P. Bishop Museum, Honolulu

CAS California Academy of Sciences, Department of Entomology, San Francisco 
CSIRO Commonwealth Scientific and Industrial Research Organisation, Australian National Insect collection, Canberra

Moul Personal collection of Mr. M.S. Moulds, Greenwich, Australia

MSNG Museo Civico di Storia Naturale "G. Doria", Genova

MZB Museum Zoologicum Bogoriense, Bogor

NCSU North Carolina State University insect collection, Raleigh

RMNH Nationaal Natuurhistorisch Museum (formerly: Rijksmuseum voor Natuurlijke Historie), Leiden

SMD Staatliches Museum für Tierkunde, Dresden

SMN Staatliches Museum für Naturkunde, Stuttgart

TMB Természettudományi Múzeum, Budapest

UPNG University of Papua New Guinea, Port Moresby

ZMA Instituut voor Taxonomische Zoölogie (Zoölogisch Museum), Amsterdam

ZMB Institut für spezielle Zoologie und Zoologisches Museum der Humboldt-Universität, Berlin

The following geographical sources have been used: Atlas van tropisch Nederland (Anonymous, 1938), The Times Atlas of the World (Anonymous, 1968), Papua New Guinea a travel survival kit (Wheeler, 1988), and a "List of New Guinea localities" published by the Bernice P. Bishop Museum (Anonymous, 1966).

After overnight softening, the male genitalia were examined by pulling out the pygofer with a sharp needle inserted between the pygofer and the eighth abdominal segment. The aedeagus was pulled out at the same time, by inserting the needle between the claspers. For all specimens, body length and tegmen length were measured; other measurements are based on a maximum of ten specimens.

\section{Phylogeny}

\section{The monophyly of Guineapsaltria}

The lateral crests of the aedeagus of Guineapsaltria curve upwards at their distal ends, and fuse to form a small dorsal protrusion near the apex of the aedeagus (cf. Fig. 22). Such a subapical protrusion is found in several related genera (e.g. several species of Aedeastria De Boer, 1990; unpublished). In Guineapsaltria, however, this protrusion is larger than in related genera and distinctly protruding; the lateral crests of the aedeagus are somewhat amplified and curved back at their distal ends. This enlarged, somewhat lobate, subapical protrusion, sometimes with two backwards curving lobes (cf. Fig. 82), and sometimes fused to a single lobe (cf. Fig. 23), is regarded apomorphous for Guineapsaltria. The swollen subapical protrusion on the aedeagus of $G$. chinai (Fig. 71) is supposed to be a modification of the more lobate protrusions.

\section{The phylogenetic position of Guineapsaltria}

Guineapsaltria belongs to the "Baeturia and related genera complex", a supposedly monophyletic group containing several New Guinean and Australian genera and some undescribed New Guinean species groups (De Boer, 1990). An S-curved aedeagus with wing-shaped lateral crests is regarded apomorphous for that complex. Though in some species of Guineapsaltria the aedeagus is almost straight, the S-curvature can generally still be recognized. Some attempts have already been made to reveal some of the intergeneric relationships of this complex (De Boer, 1990; 1991; 1992), but, since the sister group of the complex is still unknown, it is often not possible to determine characters as either apomorphous or plesiomorphous.

A first subdivision was made based on male operculum size; in Baeturia, Gymnotympana Stål, 1861, Scottotympana De Boer, 1991, and Venustria Goding \& Froggatt, 1904, the medial margin of the operculum lies medial to the meracanthus, while the medial margin of the operculum lies generally lateral to the meracanthus in Aedeastria, Thaumastopsaltria Kirkaldy, 1900, a presumed monophyletic group containing Chlorocysta Goding \& Froggatt, 1904, Glaucopsaltria Goding \& Froggatt, 1904, and Owra Ashton, 1912, and a presumed monophyletic group containing Cystosoma Westwood, 1842 and Cystopsaltria Goding \& Froggatt, 1904. Guineapsaltria shares the small operculum with the latter group of genera, but its operculum is generally much shorter and less angular; the lateral margin of its distal part makes a larger angle with the distal margin and with the crest of the basal part. A similarly shaped operculum as in Guineapsaltria is also found in several species at present included in Baeturia (B. famulus Myers, 1928, $B$. phyllophora Blöte, 1960, and B. ustulata Blöte, $1960)$ and in a number of undescribed species related to these Baeturia species.

The surface of head and pronotum and the hind margin of the tegmen suggest a second major subdi- 
vision. Aedeastria, Cystosoma, Cystopsaltria, and Thaumastopsaltria share a somewhat wrinkled head and pronotum, a fairly distinct medial fissure of the pronotum, and a very narrow border along the hind margin of the tegmen. The surface of head and pronotum is much more smooth, the pronotum misses a distinct medial fissure, and the border along the hind margin of the tegmen is generally broader in Baeturia, Chlorocysta, Guineapsaltria, Glaucopsaltria, Gymnotympana, Owra, Scottotympana, and Venustria.

The species of Guineapsaltria have a very broad vertex, with the small ocelli extremely wide apart; the distance between the lateral ocelli is distinctly larger than the distance between lateral ocellus and eye. The species of Chlorocysta and most species of Gymnotympana have a similarly broad vertex; Guineapsaltria is probably closely related to these two genera.

\section{Ingroup phylogeny}

Possible phylogenetic relationships between the species of Guineapsaltria are indicated by the possession of shared characters. When appropriate, the occurrence of these characters outside the genus is mentioned. A phylogenetic reconstruction of Guineapsaltria will be attempted when the revision of the "Baeturia and related genera complex" is completed.

Postclypeus. - The postclypeus distinctly protrudes beyond the vertex lobes in G. chinai, G. flaveola, G. stylata, and in some New Guinean specimens of G. flava; its anterior margin (dorsal view) sharply curves back at the lateral corners and forms an almost right angle with the anterior margins of the vertex lobes (Fig. 4). The postclypeus of these species forms a sharp edge along its anterior margin and is not swollen ventrally; the anterior margin (lateral view) is often concave (Fig. 63).

G. pallida, G. pallidula, G. pennyi, and G. viridula share a generally more smoothly rounded frontal edge of the postclypeus, with anterior margin (dorsal view) continuous, or almost continuous, with anterior margins of the vertex lobes (Fig. 51).
Furthermore, the postclypeus of these species is distinctly swollen ventrally, with anterior margin (lateral view) convex (Fig. 52).

G. flava is often intermediate in these respects. In most specimens the postclypeus does not protrude angularly beyond the vertex lobes, while the sharply edged anterior margin makes an obtuse angle with the anterior margins of the vertex lobes. The postclypeus of $G$. flava is slightly swollen ventrally, with anterior margin (lateral view) almost straight (Fig. 9).

The lateral sides of the postclypeus of most species of Guineapsaltria, and of nearly all species of the genus complex, have several rows of short parallel ridges forming a band along the lorum. In G. pallidula, G. pennyi, and G. viridula these rows of ridges are generally restricted to an inflated crest along the lorum; G. pallida and the type specimens of $G$. pennyi share this inflated crest, but these two species lack the rows of parallel ridges. The phylogenetic value of these postclypeal characters is not clear, since both are found in related genera. The inflated crest along the lorum, however, is probably unique for the species mentioned above.

Tegmina. - The species of Guineapsaltria share a distinct and hyaline border along the hind margin of the tegmen. In G. pallida, G. pallidula, and $G$. stylata this border is somewhat narrower, and in $G$. chinai slightly broader, than in the other species. This character varies strongly among the related genera.

Tymbal size. - G. chinai has relatively large tymbals, extending over almost half the body width (in lateral view). G. pallida and G. stylata share a very small tymbal, in lateral view extending over just about $1 / 3$ of the body width. The tymbal of other species of Guineapsaltria is variable but of intermediate size. The character seems of no great phylogenetic value, as genital characters strongly contradict a close relationship between $G$. pallida and $G$. stylata. Similar variations in tymbal size were observed in Thaumastopsaltria (cf. De Boer, 1992).

Male operculum. -Differences exist not so much in 
shape or size as in the position of the opercula. In G. chinai, G. flava, G. flaveola, G. pallidula, and G. pennyi, the distance between distal margin of operculum and abdomen is very large; the operculum does not extend over the tymbal cavity, and the folded membrane between tymbal and 1st sternite is clearly visible in ventral view. In the other species of Guineapsaltria, the operculum does partly cover the tymbal cavity in ventral view, so that most of the folded membrane, which tends to be more steeply curved inwards into the tymbal cavity, is hidden under the operculum (cf. Figs. 10 \& 33).

Similar species-specific differences were observed in several related genera (e.g. Chlorocysta and Thaumastopsaltria); their phylogenetic significance is not clear.

Slight differences exist in the shape of the crest around the distolateral corner of the basal part of the operculum. The lateral part of this crest is short and knobby in G. flaveola, G. stylata, and some specimens of $G$. flava.

The operculum of $G$. chinai is elongate medially (Fig. 64) and the medial margin of the operculum is distinctly longer than in other species of Guineapsaltria, almost as long as the meracanthus.

Abdomen. - G. flava, G. flaveola, G. stylata, and $G$. viridula show a narrow gap between the 1st and 2nd sternite. These sternites are adjacent in other species of the genus. Similar differences occur in several related genera (e.g. Thaumastopsaltria, cf. De Boer, 1992) and are generally species specific.

Pygofer. - G. chinai, G. flava, G. flaveola, and $G$. stylata have a distinctly swollen protuberance on the pygofer lobe; globular and knobby in G. styla$t a$, more angular and elongate in $G$. flava and $G$. flaveola, and weakly developed and bluntly rounded in G. chinai. In other species of Guineapsaltria the pygofer lobe curves laterally towards the ventral margin of the pygofer, forming a broad oblong and laminiform protuberance.

The ventral part of the pygofer is pressed inwards in G. flava, G. flaveola, and especially in G. stylata. The ventral half of the pygofer opening (seen from behind) is very narrow in these species, and the margins are strongly concave (Fig. 17). This character is presumably synapomorphous for these three species.

Clasper shape. - The clasper of G. chinai, G. palli$d a, G$. pallidula, and $G$. viridula is almost triangular in lateral view, with a slight lateral impression near the thorn-shaped apex (cf. Fig. 57); this clasper shape is regarded synapomorphous for these four species.

G. flava, G. flaveola, and G. stylata share a very long and slender, weakly downwards curving clasper, with bluntly rounded apex and weakly developed ventral hollow. The proximal part of the clasper forms a shaft around the aedeagus (cf. Fig. 18); the claspers are fused dorsally for a considerable length, between the point where the aedeagus reaches through the claspers, and the base of the anal valves. This clasper shape is regarded synapomorphous for these three species, though similarly fused claspers were found in Aedeastria latifrons Blöte, 1960 (De Boer, unpublished), so the phylogenetic significance of that character is not clear. G. stylata has a triangle-shaped ventral protrusion on the clasper (Fig. 35), which is absent in $G$. flava and $G$. flaveola. The latter two species share an almost identical clasper, however, that of G. flaveola is longer.

Aedeagus. - Large differences exist in the orientation of the aedeagus, caused by clasper differences. In $G$. flava, G. flaveola, and $G$. stylata, the proximal parts of the claspers form a shaft around the aedeagus. The aedeagus is directed posteriad, running almost parallel to the claspers, its apex often reaching to, or beyond, the apex of the claspers (cf. Fig. 35). This character is probably synapomorphous for these three species. Other species of Guineapsaltria have a more erect aedeagus. The aedeagi of $G$. chinai, $G$. pennyi, and $G$. viridula pass between the proximal parts of the claspers, closely adjacent to the base of the anal valves (cf. Fig. 58). The aedeagi of $G$. pallida and $G$. pallidula pass between the claspers at about half-length between clasper apex and anal valves; however, the apical part of the aedeagus often recurves to the anal valves (Figs. 75-76).

The aedeagi of G. pallida, G. pennyi, and $G$. 
viridula are sharply upcurved at half-length and have broadly rounded lateral crests. $G$. stylata has a long, slender and almost straight aedeagus with very weak lateral crests. G. flava and $G$. flaveola also have an almost straight, but shorter aedeagus, with slender but distinct lateral crests.

The aedeagi of the species of Guineapsaltria are conspicuous by their large subapical lobes. These lobes are recurving and amplified distal extensions of the lateral crests. $G$. chinai is the only species in which a connection between lateral crests and subapical lobe is not obvious; the lobe seems to be an extension of a middorsal ridge (Fig. 71). Similar subapical lobes can be found in several related species groups (e.g. Aedeastria and some undescribed genera). In these groups the lobes are generally less distinct, but on the other hand the large shieldshaped outgrowth of the aedeagus of Aedeastria cobrops De Boer, 1990, is probably a homologous structure (see De Boer, 1990).

The aedeagi of $G$. pallida, G. pallidula, and of a strongly aberrant specimen with a locality label "British New Guinea" and attributed to G. pennyi, have paired subapical lobes. The lateral crests narrow distally, but amplify and recurve at the apical bending point of the aedeagus, and continue as closely adjacent ridges towards the aedeagal apex (Figs. 82, 92, 109). In the other species of Guineapsaltria, with exception of the strongly deviating $G$. chinai, the amplified distal ends of the lateral crests fuse over the aedeagus to a collar around the apical bending point. This collar has a medial incision in G. flaveola, G. pennyi, G. stylata, G. viridula, and some specimens of G. flava (cf. Fig. 29), but forms a rounded lobe in other specimens of $G$. flava (Fig. 23).

The apex of the aedeagus is very delicate and, due to its exposed position, often damaged. In almost all species of Guineapsaltria the aedeagal apex is medially incised (cf. Fig. 23), though in some specimens of G. pallida only the underside of the aedeagus pore margin is incised (Fig. 81). The aedeagal apex of $G$. chinai strongly deviates, is slightly upcurved, sharply pointed, and definitely not incised. The aedeagus pore is oval, and at one side pointed (Fig. 71). A very similar aedeagal apex was found in several species of Thaumastopsaltria (De Boer, 1992).
Conclusion. - G. flava, G. flaveola, and G. stylata form a monophyletic group, with long, slender, dorsally fused claspers and a posteriorly directed aedeagus as synapomorphies. G. flava and G. flaveola are almost certainly sister species, only differing in clasper length.

Also G. chinai, G. pallida, G. pallidula, and $G$. viridula presumably form a monophyletic group on account of a shared clasper shape, though $G$. chinai rather deviates in many respects and the postclypeus shape of that species suggests a close relationship with G. stylata. G. pallida and G. pallidula are presumably sister species, as is suggested by an almost identical clasper and similarly paired lobes at the aedeagal apex. The latter character is also found in a specimen attributed to $G$. pennyi.

The phylogenetic position of $G$. pennyi is not clear. The specimens attributed to that species might equally well belong to 3 or 4 different species (see remarks preceding its description). The large and sharply edged clasper hollow of $G$. pennyi is presumably a plesiomorphous character. The shape and colouration of the body, and the weakly swollen postclypeus with its inflated crest along the lorum suggest a close relation to G. pallida, G. pallidula, and G. viridula.

\section{Biogeography}

The genus Guineapsaltria is distributed throughout

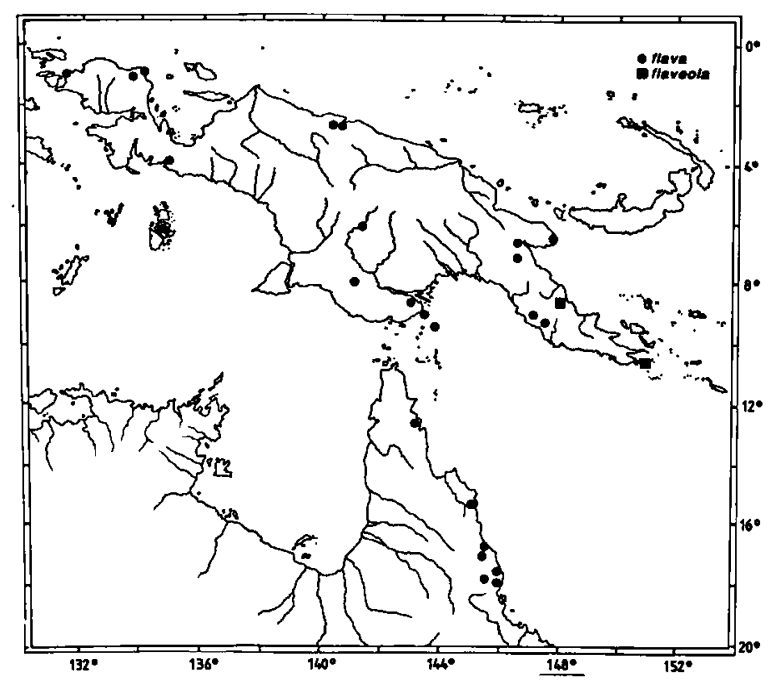

Fig. 1. Localities of Guineapsaltria flava and G. flaveola. 


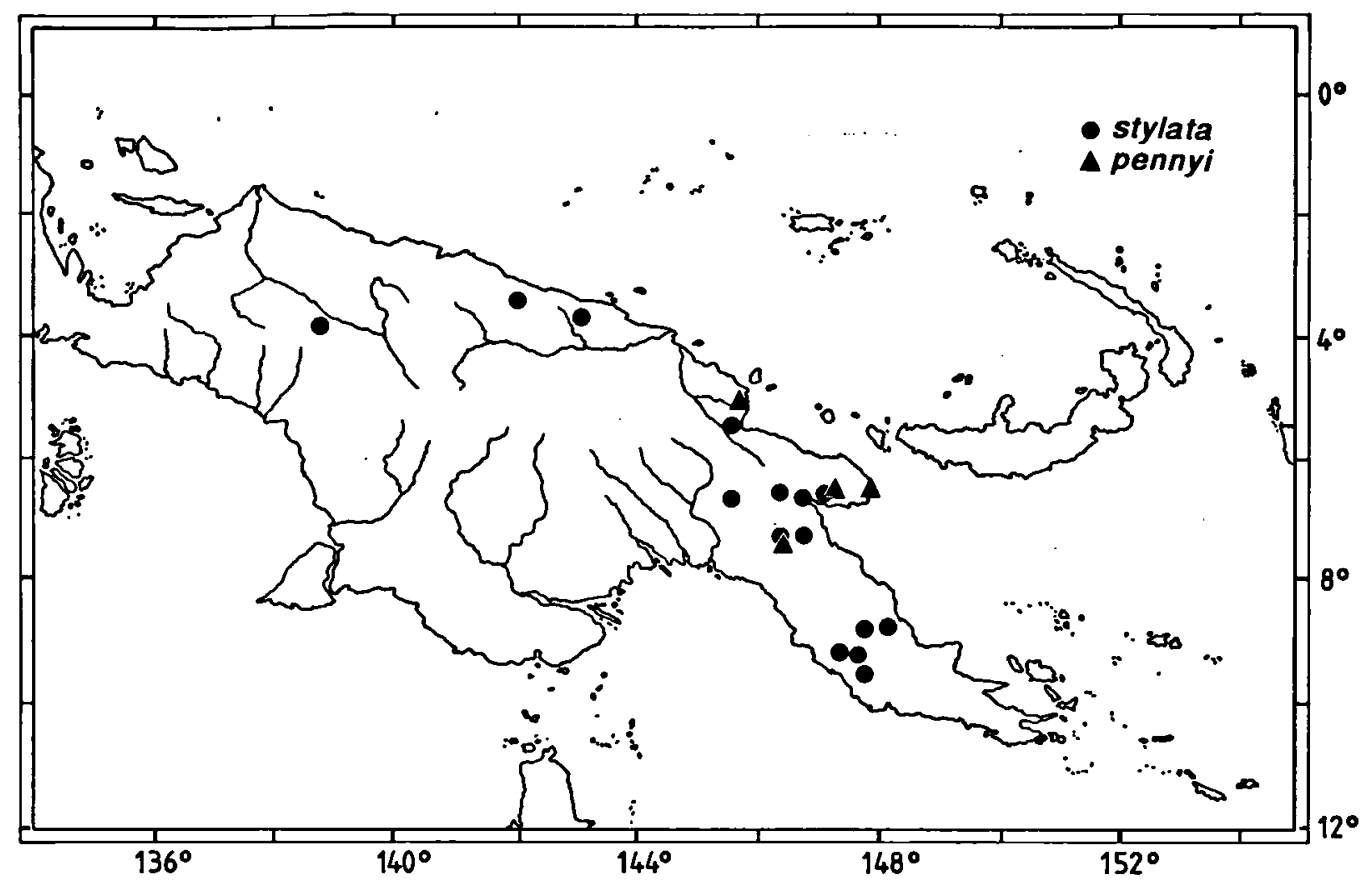

Fig. 2. Localities of Guineapsaltria stylata and G. pennyi.

New Guinea, though it is not found in the central mountain ranges. Outside New Guinea its distribution area includes Manus Island, Umboi Island, New Britain, and the eastern parts of the Cape York Peninsula of Queensland. Most species seem to be concentrated in the northern mountain ranges of New Guinea and on the Papuan peninsula.

G. flava shows an extremely wide distribution (Fig. 1) along the east coast of the Cape York Peninsula (Queensland), in the Torres Straight, southeastern New Guinea, the Papuan and Huon Peninsulas, Cendrawasih, and Hollandia and Ifar in northern New Guinea. Two females from the Aru islands probably belong to this species. It is not clear whether this scattered distribution area represents actual disjunctions in northwestern Irian Jaya and northern Papua, or is due to undercollecting. Possibly G. flava is rare or difficult to collect, at least in New Guinea. Whereas several other, widely distributed, species (e.g. G. stylata and $G$. viridula) are known from larger series, $G$. flava is represented by only one or two specimens at each locality. According to Moulds (1990) G. fla- $v a$ is a very common species in parts of Queensland, and abundantly caught at light. More interesting from a biogeographic point of view, is the total absence of $G$. flava in the central mountain ranges. Though Moulds (1990) remarks that $G$. flava is a lowland species, not exceeding altitudes of $500 \mathrm{~m}$ in Australia, it was collected from over $1200 \mathrm{~m}$ in Wau (Papua New Guinea). G. flava is one of the very few New Guinean cicada species occurring on both sides of the central mountain ranges. A similar distribution was found for Aedeastria latifrons (Blöte, 1960), but this species does not reach Australia or Cendrawasih (De Boer, unpublished).

Four species, G. pallida, G. pallidula, G. stylata, and $G$. viridula, share a wide distribution throughout northern New Guinea (Figs. 2-3), with $G$. stylata and $G$. viridula continuing in the Papuan peninsula. The distribution area of $G$. viridula further includes Umboi Island and the Gazelle peninsula of New Britain. Such a distribution pattern, throughout northern New Guinea and the Bismarck Archipelago, seems fairly common among cicadas. Comparable distributions were recorded for Dice- 


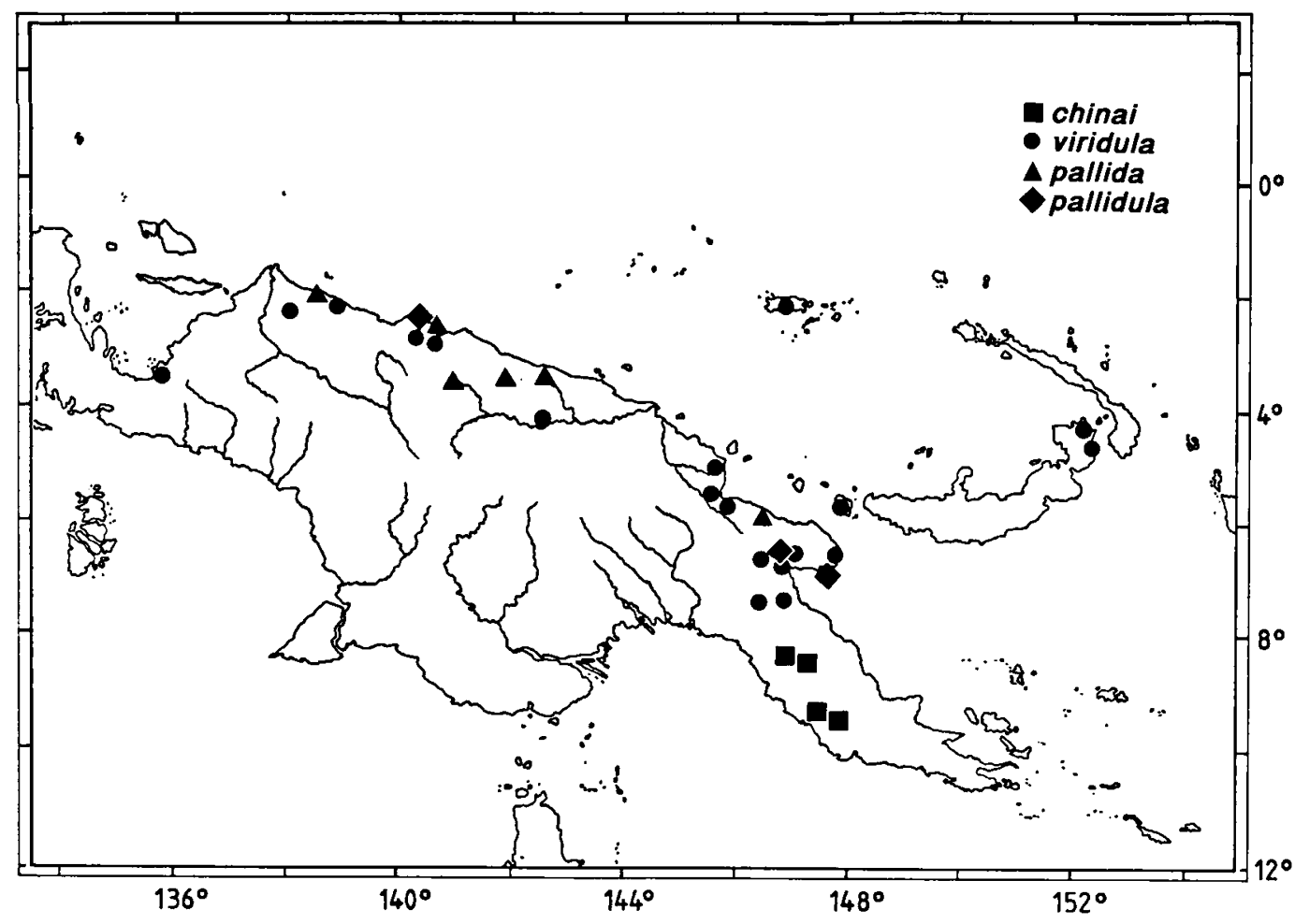

Fig. 3. Localities of Guineapsaltria chinai, G. viridula, G. pallida, and G. pallidula.

ropyga bihamata Duffels, 1977 (cf. Duffels, 1977), Baeturia parva Blöte, 1960 (cf. De Boer, 1982), Gymnotympana dahli (Kuhlgatz, 1905), and Gymnotympana rubricata (Distant, 1897) (De Boer, unpublished).

G. pennyi has a more limited distribution in northern New Guinea; the species seems restricted to northeastern Papua, including the Huon peninsula.

G. chinai and G. flaveola are endemics of the Papuan peninsula, with $G$. flaveola also recorded from Sideia Island, just east of the eastern point of the Papuan peninsula. The Papuan peninsula is particularly rich in endemic cicadas, but most of these species are still undescribed.

\section{Taxonomy}

Guineapsaltria n. gen.

Type species: G. flava (Goding \& Froggatt, 1904)

\section{Description}

Remark: For this study, only museum material could be examined. The body colour of this material ranges from reddish brown to greenish, but is predominantly some shade of ochraceous brown. In his book on Australian cicadas, Moulds (1990) describes $G$. flava, the only species of this genus represented in Australia, as green. In fact, Australian children know this species as the "green fairy". It is very likely that the colour of fresh material of all species of this genus is green.

Body somewhat stained, but almost uniformly coloured, without any distinct marks, though abdomen sometimes with reddish segmental hind margins. Females of most species, on average, slightly smaller than males, but with more robust head and thorax, and slightly longer tegmina. Tegmina of males 1.1-1.4 times as long as body length, of females 1.2-1.5 times as long. Male abdomen 1.1-1.6 times as long as head and thorax, of females 1.0-1.3 times as long.

Head broad and short and quite flat (Figs. 4, 51), 

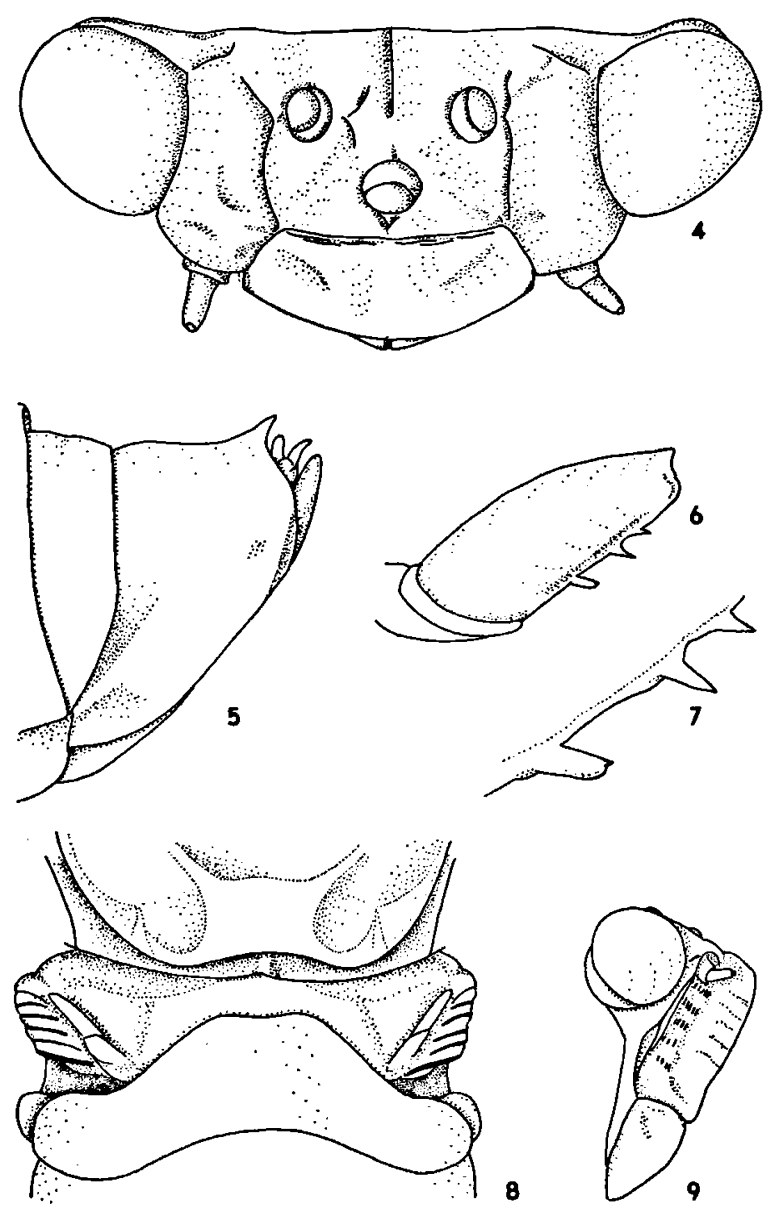

Figs. 4-9: 4, head in dorsal view, Guineapsaltria stylata, Singwava River; 5, female genital segment in lateral view, Guineapsaltria flava, Daru; 6, fore femur, G. flava, Oriomo; 7, detail spines on fore femur, $G$. flava, Oriomo; 8, first and second tergite, G. flava, Oomsis; 9, postclypeus in lateral view, G. flava, Kebar valley.

2.2-3.3 times as wide as long and 1.7-2.0 times as wide as distance between eyes. Postclypeus broad and short, 2.0-4.1 times as wide as long, oblong in dorsal view, either with broadly convex anterior margin, or protruding in obtuse angle. Sides of postclypeus with some weak furrows and, in all species but $G$. pallida and $G$. pennyi, with short rows of short parallel ridges in a narrow band along the lorum. In some species this band forms a distinctly inflated crest. Vertex very broad, only slightly vaulted, with shallow medial fissure and the small ocelli wide apart. Diverging fissures from centre of head to corners of postclypeus weakly developed, or completely absent. Vertex 1.7-2.6 times as wide as long; $1.2-1.7$ times as wide as postclypeus and 1.8-2.8 times as wide as eye. Distance between lateral ocelli 2.2-4.1 times width of frontal ocellus and distinctly larger (1.2-2.0 times as large) than distance between lateral ocellus and eye. (In $G$. chinai, the only aberrant species, these ratios are 2.0-3.1 $\times$ and 0.8-1.0 $\times$, respectively.)

Pronotum 2.3-2.8 times as wide as long and with very weak middorsal furrow. Pronotal collar laterally angularly amplified and slightly curving down at its anterior margin.

Tegmina and wings hyaline. Tegmina with 8 apical areas. A very distinct and hyaline costal area gradually broadens towards tegmen apex. Distinct hyaline border present along hind margin of tegmen, slightly variable in width between the species. Wings with 6 apical areas and distinctly broader hyaline border.

Legs ochraceous and unmarked. Fore femur with row of 3, occasionally 4, erect and sharply pointed spines (Figs. 6-7).

Tymbal with 5 or 6 parallel sclerotized ridges from dorsal to ventral margin, a proximal ridge that almost reaches ventral margin, and often a most proximal ridge reaching to only half the tymbal width. Short intercalary ridges can often be discerned, forming a darkened band at half-width across the tymbal.

Opercula very small. Basal part of operculum slightly vaulted with two rounded elevations, and upcurved at distolateral corner, into a distinct crest rounding that corner. Distal part of this crest rather long and slender, before gradually amplifying into distal part of operculum. Distal part of operculum angularly oblong, generally shorter than basal part and in males not, or only partly, covering tymbal cavity in ventral view. Its lateral margin straight and slightly directed mesiad, forming an obtuse, though often rounded, angle with crest of basal part and with distal margin. Distal margin straight, but often concave near distomedial corner (cf. Fig. 33). The operculum of $G$. chinai is of a distinctly different shape; nearly triangular, with long medial margin (Fig. 64). Operculum shorter than meracanthus and not extending medially beyond meracanthus; its medial margin lies laterally of meracan- 
thus. Female operculum shorter, but generally of same shape as that of male.

Male abdomen very delicate, hardly inflated, in shape hardly differing from that of female. First tergite in male very short medially, sometimes hidden under metanotum. Dorsal part of second tergite about twice as long as lateral parts, proximal margin of second tergite very weakly concave medially (Fig. 8) and almost straight between auditory capsules and sternite 2 (cf. Fig. 10). Lateral parts of 2nd tergite weakly swollen at anterior margins and adjacent to tymbals. Sternites 1 and 2 adjacent, or nearly adjacent. Auditory capsules well developed, laterally protruding and visible in dorsal view.

Female abdomen more robust than that of male, with short and broad pygofer. Ovipositor sheaths reaching just beyond apex of caudodorsal beak.

Male pygofer globularly rounded. Caudodorsal beak short and straight, generally quite broad in lateral view and erect; not curved over basal part of claspers or anal valves. Ventral parts of pygofer often curved inwards along pygofer opening, ventral edges somewhat rounded. Claspers directed posteriad, reaching well beyond pygofer, generally parallel but in $G$. viridula diverging towards apices. Claspers often fused at base, forming a continuous ring-shaped collar around base of anal valves. Aedeagus straight or upcurved, but in most species angularly bent down near apex. Lateral crests of aedeagus, sometimes very slender, curving upwards at distal ends and forming lobate protrusion at apical bending point of aedeagus. Apex of aedeagus in most species slightly incised.

\section{Key to the males}

1a. Clasper broad and triangular in lateral view, gradually narrowing towards sharply pointed thorn-shaped apex ....2

b. Clasper broad at base, but abruptly narrowing towards long and slender apical part; bluntly rounded or sharply pointed, but not thorn-shaped at apex $\ldots \ldots \ldots \ldots \ldots \ldots \ldots 5$

2a. Aedeagus passing between most proximal part of claspers, adjacent to anal valves. Tegmina with very distinct hyaline border along hind margin. Clasper base forming a high collar around base of anal valves; dorsal margin of clasper forming a right angle with this collar ........... 3

b. Aedeagus passing between claspers, at about half-length of claspers, but recurving and with apex adjacent to anal valves. Tegmina with fairly narrow hyaline border along hind margin. Clasper base not forming a distinct collar; dorsal margin of clasper gradually curving to base of anal valves

3a. Claspers diverging towards apices. Subapical protrusion of aedeagus incised, not inflated and recurved. Postclypeus smoothly rounded anteriorly and distinctly swollen ventrally ............................... G. viridula

b. Claspers parallel towards apices. Subapical protrusion of aedeagus not incised, globularly inflated and directed towards aedeagal apex. Postclypeus with sharply edged anterior margin and not swollen ventrally ....... G. chinai

4a. Aedeagus almost straight, with slender lateral crests, but strongly Z-curved near apex, and with distinct subapical lobes (Fig. 92). Postclypeus with short rows of parallel ridges along lorum ................ pallidula

b. Aedeagus strongly upcurved, with broad lateral crests, weakly curved near apex, and with weakly developed subapical lobes (Figs. 81-83). Postclypeus without rows of parallel ridges along lorum ................. pallida

5a. Clasper with large, sharply edged, ventral hollow ...... $\ldots \ldots \ldots \ldots \ldots \ldots \ldots \ldots \ldots \ldots$ G. pennyi

b. Clasper with weakly developed ventral hollow ......6 6

6a. Clasper with angular ventral protrusion. Aedeagus long and slender. Tegmina with fairly narrow hyaline border along hind margin $\ldots \ldots \ldots \ldots \ldots \ldots \ldots \ldots$. stylata

b. Clasper without ventral protrusion. Aedeagus quite short. Tegmina with distinct hyaline border along hind margin .............................. 7

7a. Clasper angularly bent at about $2 / 3$ of its length (Fig. 26)

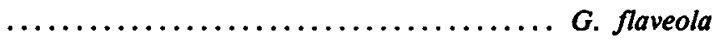

b. Clasper not angularly bent (Fig. 18) ......... G. flava

\section{Description of the species}

Guineapsaltria flava (Goding \& Froggatt, 1904) n. comb.

(Figs. 1, 5-24)

Synonymy. - Comparison of the holotypes of Baeturia modesta Distant and Baeturia minuta Blöte revealed that $B$. minuta and $B$. modesta are synonyms. $B$. modesta was recently brought into the synonymy of Tibicen flavus Goding \& Froggatt (Moulds, 1990). Information on the lectotype of $T$. flavus is given by Moulds (1990).

Tibicen flavus Goding \& Froggatt, 1904: 610-611. Abricta? flava; Distant, 1906: 131; Burns, 1957: 636. Abricta flavus; Kirkaldy, 1907: 308.

Baeturia flava; Moulds, 1990: 182-183.

Baeturia modesta Distant, 1907: 418; Blöte, 1958: 167, fig. 11; Metcalf, 1963: 250; Duffels \& Van der Laan, 1985: 253.

Baeturia minuta Blöte, 1960: 73, Fig. 29; Duffels \& Van der Laan, 1985: 253.

Baeturia exhausta Guerin; Myers, 1928: 60, partim: Torres Strait.

Baeturia stylata Blöte, 1960: 76, partim: Endeavor River. 
Material examined. - Irian: New Guinea (W.): Bewani Mts., Humboldt Bay Dist., ix.1937, w. Stüber, 1 \&, BMNH; Erambu, 80 km ex Merauke, 29.i.1960, T.C. Maa, 1 o, 1 \&, ZMA; Etnabaai, 16-20.vii.1939, Nieuw Guinea Exped. K.N.A.G. [Koninklijk Nederlands Aardrijkskundig Genootschap] 1939, $1 \%$, RMNH; Hollandia, 23.ii.1952, L.D. Brongersma, ơ holotype Baeturia minuta, RMNH; Hollandia, 13.iii.1960, T.C. Maa, 1 o , BPBM; Ifar, Cyclops Mts., 300 m, 24.xi.1958, J.L. Gressitt, 1 \&, BPBM; Kebar Val., W. Manokwari, Vogelkop, 550 m, 4-31.i.1962, S. \& L. Quate, 1 \%, BPBM; Kiunga, Fly R., 55 m, viii.1969, J. \& M. Sedlacek, 1 \&, BPBM; Manokwari $134^{\circ} 5^{\prime} \mathrm{E} 0^{\circ} 52^{\prime} \mathrm{S}, 1954$, J.C. Bauwens, $1{ }^{\circ}$, RMNH; Sorong, S.vi-7.vii.1948, M.A. Lieftinck, $1 \sigma$, MZB; Waris, S. of Hollandia, 50-500 m, 8-15.viii.1959, T.C. Maa, 1 \&, BPBM.

Aru Islands: Aru, Wallace, 67/66, 1 ९, BMNH; Aru Isl., 1 \& det. famulus Stål, BMNH.

Papua: New Guinea (N.E.): Finschhafen, 1891, Fruhstorfer, 1 o, BMNH; Oomsis, 22 mi. W. Lae on Lae - Bulolo Rd., Morobe Dist., $100 \mathrm{~m}, 26$. iv.1959, Sixth Archbold Exped. to Papua New Guinea, L. J. Brass, 1 o , AMNH; Wau, 1150-1200 m, 31.i.1966, J. Sedlacek, 1 \& , BPBM; Wau Area, Morobe P., iii-iv.1984, T.R. New, 1 \&, Moul; Wau, Morobe Prov., 24-25.xi.1979, J.H. Martin, 2 ८ \&, BMNH; Wau, Mt. Missim, Morobe Dist., 1200-1800 m, 8.xii.1963, H. Clissold, $1 \sigma$, BPBM.

New Guinea (S.E.): Bujakori, viii.1890, Loria, $1 \sigma^{\circ,} 3$ ९ , MSNG; Daru Isl., 3 m, 30.i.1964, H. Clissold, 1 १, ВPBM; Koitaki, 5-12.v.1921, E.O. Pockley, 1 o , AMS; Oriomo River, $6 \mathrm{~m}, 14 . i 1.1964$, H.C. [Clissold], 1 \% , BPBM; Sogeri, 11.x.1944, A. Blombery, $1 \%$, AMS.

Queensland: Queensland, 1907-50, F.P. Dodd, $\sigma$ holotype Baeturia modesta (Distant's type det. Blöte?), BMNH; same data but 1907-129, 1 \& syntype, BMNH; Cairns 9 km W., ii-iv.1985, 2 o o , ZMA; Cooktown, 27.i.1964, J. Sedlacek, 1 \&, BPBM; Cardstone [Gardstone], Kareeya Power Sta., N.W. of Tully, 22.xii.1972, M.S. \& B.J. Moulds, 1 \% Baeturia flava (Goding \& Froggatt) det. M.S. Moulds, ZMA; Darnly Isl., 1910, Elgner, 1 १, BMNH; El Arish, 9 mi E., 7.iii.1964, I.F.B. Common \& M.S. Upton, $1 \%$, CSIRO; Endeavor River, $1 \%$ allotype Baeturia stylata, det. Melampsalta flava, BMNH; Etty Bay near Innisfail, 27.i.1981, M.S. \& B.J. Moulds, 1 o Baeturia flava (Distant) det. M.S. Moulds, ZMA; same data but 13.xii.1988, 1 ○ Baeturia flava (Goding \& Froggatt) det. M.S. Moulds, ZMA; Gardstone nr. Tully Falls, 9.i.1962, E.B. Britton, 2 \& , BMNH; Iron range, 2.i.1973, M.S. Moulds, 1 \% Baeturia flava (Goding \& Froggatt) det. M.S. Moulds, ZMA; Julatten, 21.i.1981, M.S. \& B.J. Moulds, 1 o Baeturia flava (Distant) det. M.S. Moulds, ZMA; Hambledon, xi.1921, Pemberton, 1 \&, BPBM.

Remarks. - G. flava is a very small-sized species. It can be recognized by its straight, slender and apically rounded claspers.

Description. - Body ochraceous brown, sometimes partly tinged with green, but (according to Moulds, $1990)$ entirely olive green when alive. Females on average slightly smaller than males, but with more robust head and thorax. Abdomen of males 1.2-1.6 times as long as head and thorax, of females 1.1-1.2 times as long. Male tegmen 1.1-1.4 times as long as body length, of females 1.2-1.3 times as long.

Head: Ochraceous, often slightly reddish towards anterior margins of vertex lobes. Postclypeus sharply edged frontally and angularly protruding, its anterior margin angularly bent medially. Postclypeus in some specimens distinctly protruding beyond vertex lobes, with anterior margin of postclypeus angularly bending back at lateral corners and forming an almost right angle with anterior margins of vertex lobes (cf. Fig. 4), but generally anterior margin making an obtuse angle with anterior margins of vertex lobes. Postclypeus slightly swollen, anterior margin (lateral view) straight or slightly convex. Lateral sides of postclypeus quite smooth, but with about 5 or 6 indistinct rows of short parallel ridges (Fig. 9).

Legs: Fore femur with row of three pointed spines, diminishing in length towards tibia (Figs. 6-7).

Tegmina: Hyaline border along hind margin fairly broad.

Tymbal organ: Five weakly sclerotized ridges spanning the tymbal from dorsai to ventral margin, a sixth most proximal ridge almost reaching ventral margin, and sometimes a seventh spanning half the tymbal width.

Opercula: Male operculum (Fig. 10) with distal part shorter than basal part and oblong-shaped. Lateral margin straight, making an obtuse, rounded, angle with distal margin and with crest around lateral corner of basal part. Lateral part of this crest sometimes very short and knobby. Distal margin straight or slightly convex, sometimes slightly concave towards distomedial corner (cf. Fig. 33). Medial margin straight. Gap between operculum and both tymbal and abdomen very wide, folded membrane clearly visible in ventral view. Meracanthus reaching well beyond operculum, to about half-way tymbal cavity. Female operculum (Fig. 13) very similar to that of male. Distal part very 

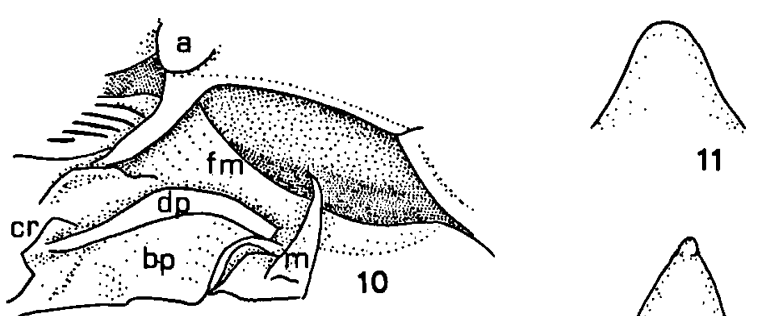

11

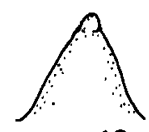

12

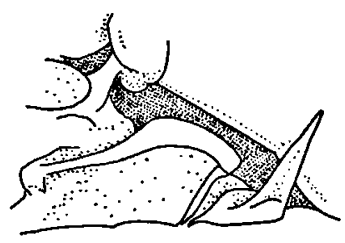

13

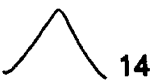

14

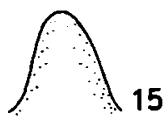

15

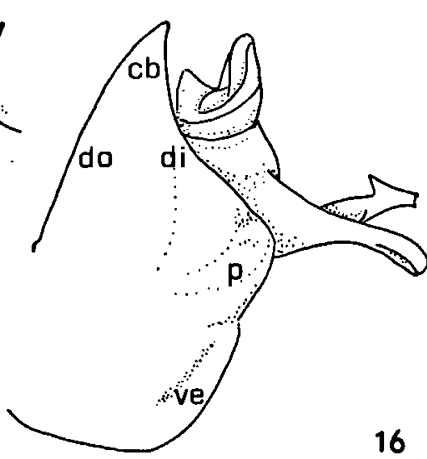

16

Figs. 10-16. Guineapsaltria flava (Goding \& Froggatt, 1904): 10 , male operculum, Oomsis; 11 , male caudodorsal beak in dorsal view, Manokwari; 12, id., Hollandia; 13, female operculum, Daru; 14, female caudodorsal beak in dorsal view, Daru; 15, id., Wau; 16, pygofer in lateral view, Oomsis. Legend: a = auditory capsule; bp = basal part of operculum; cb = caudodorsal beak; $\mathrm{cr}=$ crest around distolateral corner of basal part of operculum; $\mathrm{di}=$ distal margin of pygofer; do = dorsal margin of pygofer; $\mathrm{dp}=$ distal part of operculum; $\mathrm{fm}=$ folded membrane; $\mathrm{m}=$ meracanthus; $p=$ protuberance on lateral lobe of pygofer; ve $=$ ventral margin of pygofer.

short. Distal margin straight to rectangular distomedial corner, or slightly concave to rounded distomedial corner.

Abdomen: Uniformly ochraceous or greenish tinged. First tergite of male very short, partly hidden under metanotum medially (Fig. 8). Sternite 8 (Fig. 20) fairly long, but shorter and broader than in G. stylata (cf. Fig. 32). Female pygofer (Fig. 5) short; ovipositor sheaths reaching just beyond apex of caudodorsal beak. Female caudodorsal beak in dorsal view generally broad, triangle-shaped and pointed at apex (Fig. 14), longer and more bluntly rounded in specimen from Wau (Fig. 15).

Male genitalia: Pygofer in lateral view as in Fig. 16. Dorsal margin weakly convex, continuous with

rounding of caudodorsal beak. Distal margin straight, concavely bending into margin of beak. Ventral margin straight in lateral view, but ventral part of pygofer strongly curved inwards towards ventral margin; basal part of pygofer opening very slender, with concave margins (Fig. 17), much broader in specimen from Oomsis. Caudodorsal beak quite broad in lateral view, triangular in dorsal view, often quite narrow and sharply pointed at apex (Fig. 12), but sometimes broader and rounded (Fig. 11). Lateral lobe of pygofer almost globularly rounded, curving inwards towards distal margin. Lateral lobes with large, angular protuberances. Claspers parallel to apices. Clasper (Fig. 18) very long and slender, reaching far beyond pygofer margin, straight, but slightly curving downwards near rounded apex. Apical part of clasper with weak ventral hollow. Proximal half of claspers forming
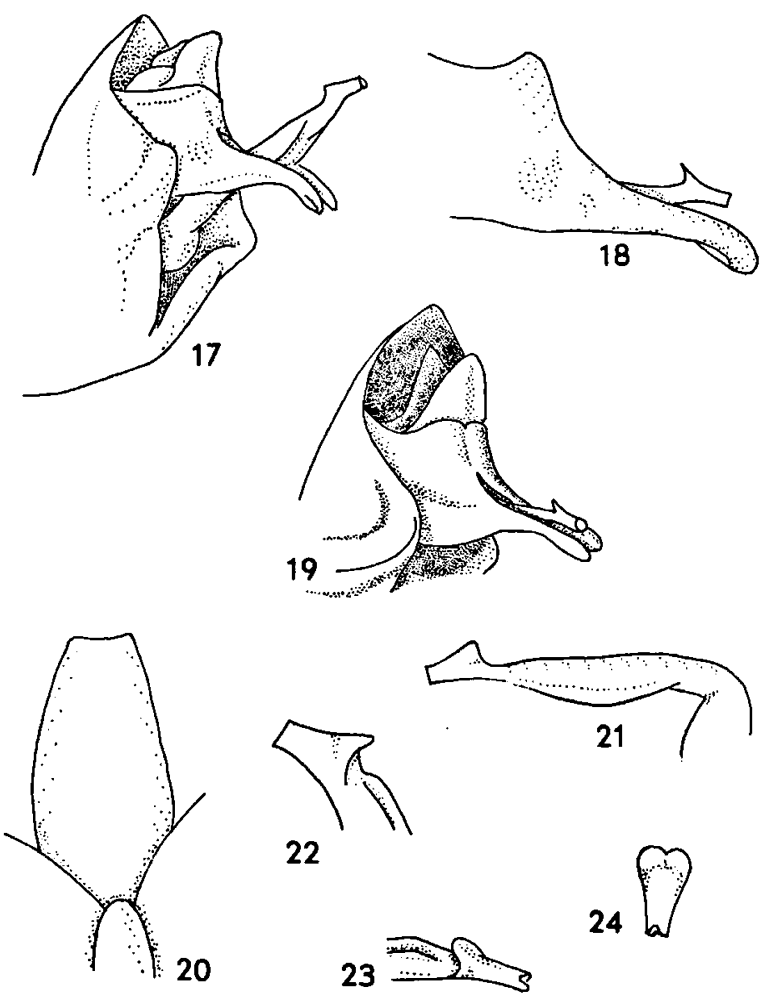

Figs. 17-24. Guineapsaltria flava (Goding \& Froggatt, 1904): 17, pygofer from aslant, Cardstone; 18, clasper, Wau; 19, pygofer and clasper from aslant, Wau; 20, eighth sternite, El Arish; 21 , aedeagus in lateral view, Oriomo; 22, detail apex of aedeagus in lateral view, Oriomo; 23 , id., Oriomo; 24 , apex of aedeagus from above, Wau. 
a shaft around aedeagus. Proximal parts of claspers fused dorsally, between aedeagus and base of anal valves, and sharply curved upwards, forming a broad and ring-shaped collar around base of anal valves (Fig. 19). Aedeagus directed posteriad, between, and parallel to, claspers, but not reaching beyond apex of clasper. Aedeagus (Fig. 21) short and almost straight, slightly bent down near apex, with slender but distinct lateral crests and, in some specimens, with distinctly paired dorsal crests. Lateral crests curve upwards towards their distal ends and fuse to slender, rounded and recurving subapical lobe (Figs. 22-23), this lobe being sometimes slightly incised (Fig. 24). Apex of aedeagus incised (Fig. 23).

Measurements. - Body length o : 12.0-15.0 mm (mean 13.5 $\mathrm{mm} \pm 1.0$ ), $\%: 12.1-15.2 \mathrm{~mm}$ (mean $13.2 \mathrm{~mm} \pm 0.9$ ); tegmen length $\sigma:$ : 14.7-17.8 $\mathrm{mm}$ (mean $16.2 \mathrm{~mm} \pm 1.1$ ), $\&: 15.4-18.2$ $\mathrm{mm}$ (mean $17.1 \mathrm{~mm} \pm 1.0$ ); head length $\sigma: 1.1-1.4 \mathrm{~mm}$ (mean $1.2 \mathrm{~mm}$ ), $:$ : $1.2-1.5 \mathrm{~mm}$ (mean $1.3 \mathrm{~mm}$ ); pronotum length $\sigma^{\circ}$ : $1.3-1.7 \mathrm{~mm}$ (mean $1.5 \mathrm{~mm}$ ), $Q: 1.5-1.8 \mathrm{~mm}$ (mean $1.7 \mathrm{~mm}$ ); mesonotum length $\sigma:$ : 2.7-3.4 mm (mean $2.9 \mathrm{~mm}$ ), $\$: 2.7-3.5$ $\mathrm{mm}$ (mean $3.1 \mathrm{~mm}$ ); head width $\sigma$ : $2.9-3.5 \mathrm{~mm}$ (mean 3.1 $\mathrm{mm}$ ), 9 : 3.1-3.7 mm (mean $3.4 \mathrm{~mm}$ ); width of pronotal collar $\sigma: 3.4-4.4 \mathrm{~mm}$ (mean $3.9 \mathrm{~mm}$ ), $९: 3.8-4.7 \mathrm{~mm}$ (mean 4.2 $\mathrm{mm})$.

Distribution (Fig. 1). - G. flava has an extremely wide distribution. The species is known from northern Queensland (Cape York Peninsula) and is widely distributed in New Guinea, with exception of the central mountain ranges and the eastern part of the Papuan peninsula. G. flava is one of the very few cicada species occurring on both sides of the central mountain ranges. Two females from the Aru Islands probably belong to this species.

\section{Guineapsaltria flaveola n. sp.}

(Figs. 1, 25-30)

Material examined. - Holotype: "New Guinea SE / Popondetta / 25 m vi.1966" (print); "Shanahan-Lippert / Light Trap Bishop Museum" (print), $\sigma$, BPBM. Paratypes: same data as holotype, $1 \sigma, 7$ \% , BPBM; same data but v.1966, 1 \%, 1 \%, BPBM; Popondetta, 22.i.1971, A. \& G. Daniels, 1 \&, Moul; Popondetta, Inbora Plant'n, 23.ix.1963, P. Shanahan, $1 \sigma$, ZMA; Sideia Island, Sideia mission, 1.i.1989, G. Hangay, 2 ơ, 5 \&, , Moul.

Other material: Sangara, Popondetta Dist., 22.iii.1956, E.S. Brown, 1 \%, BMNH.
Remarks. $-G$. flaveola is very closely related to $G$. flava; it is most probably its sister species. Males can be recognized by longer, and angularly bent, claspers. Females could not be separated from females of $G$. flava on other than geographical grounds.

Description. - The description largely follows that of $G$. flava, from which it differs in characters of male genitalia only. The Sideia material tends to be somewhat larger that the Popondetta material.

Male genitalia: Pygofer very similar to that of $G$. flava, with large and angular protuberances on lateral lobes, and inwards curving ventral margins (Fig. 27). Pygofer in lateral view (Fig. 28) with more slender and more erect caudodorsal beak. Caudodorsal beak in dorsal view (Fig. 25) triangle-shaped, pointed at apex. Claspers (Fig. 26) parallel as in G. flava, very slender, with weak clasper hollow, but distinctly longer and angularly bent down at about 2/3 of their length. Aedeagus (Fig. 30)

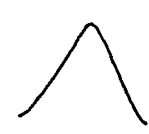

25
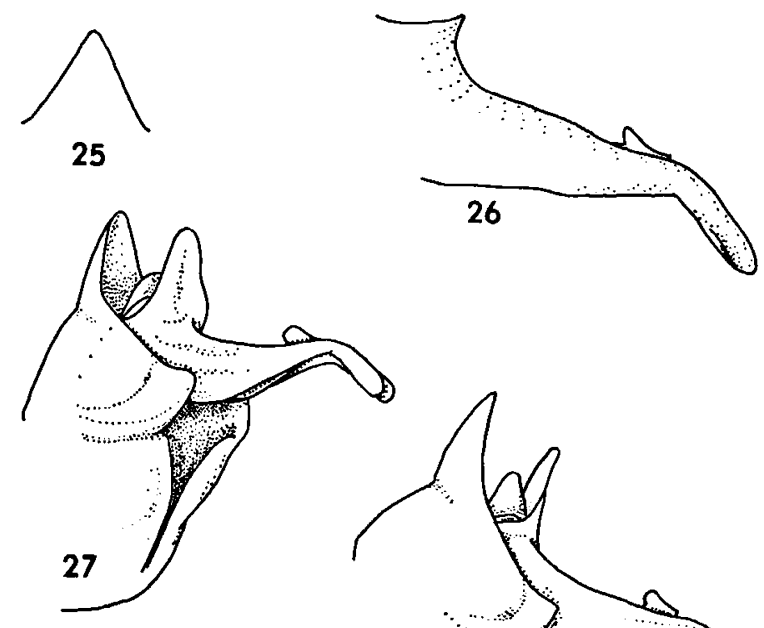

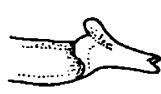

29
30

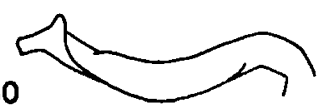

Figs. 25-30. Guineapsaltria flaveola n. sp., Popondetta: 25, male caudodorsal beak in dorsal view; 26 , clasper; 27 , pygofer from aslant; 28 , pygofer in lateral view; 29 , detail apex of aedeagus; 30 , aedeagus in lateral view. 
strongly upcurved, but in other respects very similar to that of $G$. flava, with stretched apical part and distinct lateral and dorsal crests. Subapical lobe distinctly incised medially (Fig. 29).

Measurements. - Body length $\sigma^{\prime}:$ 12.0-15.4 mm (mean 13.8 $\mathrm{mm} \pm 1.2$ ), ᄋ 12.1-15.5 mm (mean $13.2 \mathrm{~mm} \pm 1.0$ ); tegmen length $\sigma:$ : 15.1-16.8 mm (mean $16.2 \mathrm{~mm} \pm 0.7$ ), $\&: 15.6-18.7$ $\mathrm{mm}$ (mean $16.8 \mathrm{~mm} \pm 1.0$ ); head length $\sigma: 1.1-1.4 \mathrm{~mm}$ (mean $1.2 \mathrm{~mm}$ ), $\%$ : $1.2-1.6 \mathrm{~mm}$ (mean $1.3 \mathrm{~mm}$ ); pronotum length $\sigma$ : 1.4-1.8 mm (mean 1.6 mm), $\%: 1.5-2.0 \mathrm{~mm}$ (mean $1.7 \mathrm{~mm}$ ); mesonotum length $\sigma: 2.7-3.4 \mathrm{~mm}$ (mean $3.0 \mathrm{~mm}$ ), $\$: 2.7-3.7$ mm (mean $3.2 \mathrm{~mm}$ ); head width $\sigma: 3.0-3.7 \mathrm{~mm}$ (mean 3.3 $\mathrm{mm}$ ), : $3.0-4.2 \mathrm{~mm}$ (mean $3.4 \mathrm{~mm}$ ); width of pronotal collar o: : 3.4-4.5 mm (mean $4.0 \mathrm{~mm}$ ), $९: 3.9-5.4 \mathrm{~mm}$ (mean 4.4 $\mathrm{mm})$.

Distribution (Fig. 1). - G. flaveola is recorded from around Popondetta on the Papuan peninsula and from Sideia Island just east of the most eastern point of the Papuan peninsula.

Etymology. - Flaveola is derived from the Latin flavus meaning gold coloured, yellow. The name was chosen to emphasize the close relationship of this species with $G$. flava, described above.

Guineapsaltria stylata (Blöte, 1960) n. comb.

(Figs. 2, 4, 31-50)

Baeturia stylata Blöte, 1960: 75, fig. 29; Duffels \& Van der Laan, 1985: 254.

Material examined. - Irian: New Guinea (W.): Archbold Lake, Central Mts., 760 m, 26.xi-3.xii.1961, L.W. Quate, 1 \&, BPBM; same data but S. \& L. Quate, $1 \propto, 1$ \%, BPBM; 1 \%, ZMA; S. Quate, 2 \% , BPBM.

Papua: New Guinea (N.E.): Boana, 1000 m, 22.xi.1965, H. Pyka, $1 \sigma$, SMN; Bubia near Lae, 21.xii.1963, D.K. McAlpine, 1 o , AMS; Bulolo, 700 m, 6.xi.1969, J. Sedlacek, 1 \% , BPBM; same data but 26.xi.1969, 1 \&, BPBM; Busu R., E. Lae, 100 m, 13.ix.1955, J.L. Gressitt, $1 \sigma$, BPBM; same data but 14.ix.1955, 4 Q \%; 15.ix.1955, 1 \&, all BPBM; Daradae nr. Javarere, Musgrove R., 100m?, 2.x.1958, J.L. Gressitt, 1 o , 2

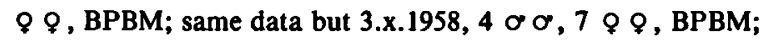

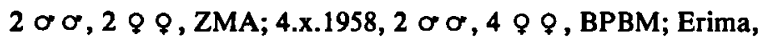
Astrolabe Bay, Biró, $1 \propto \circ, 4$ \& \%, TMB; Lae, vi.1944, F.E. Skinner, 1 ९, BPBM; Mt. Lamington Dist., Northern Division, C.T. McNamara, $1 \sigma, 2 \circ \%$, AMS; same data but 1928, 1 \% , 3 ९ ; 1929, 1 \%; i-ii.1921, 1 \%, 3 \% ९, all AMS; Mt. Lamington Dist., Northern Division, $500 \mathrm{~m}$, vi.1966, P. Shana- han \& G.E. Lippert, 1 ९ , BPBM; Maprik, 160 m, 29.xii.195917.i.1960, T.C. Maa, 2 ९ , BPBM; Purosa Camp area, Eastern Highlands District, 1950 m, 25.ix.1959, Sixth Archbold Exped. to Papua New Guinea, L.J. Brass, 1 o AMNH; Singuawa R., Lae, $147^{\circ} 10^{\prime}$ E $6^{\circ} 45^{\prime}$ S, 30 m, 5.iv.1966, O.R. Wilkes, 1 \&, BPBM; same data but 15.iv.1966, 1 \%; 16.iv.1966, 1 \%, both BPBM; Ulap, Wasu, 1200 m, 1-8.viii.1965, H. Pyka, $1 \sigma^{\circ}$, SMN; Umi River, Markham Valley, Morobe Dist., $480 \mathrm{~m}$, 18.xi.1959, Sixth Archbold Exped. to Papua, L.J. Brass, 6 ơ ơ, 1 ९, AMNH; same data but 20.xi.1959, 5 o $\sigma ;$; 26.xi.1959, 1 o, 1 \&; 28.xi.1959, 4 ơ ơ, 4 \& \&, all AMNH; 28.xi.1959, 1 o, 1 \%, ZMA; Wantipi Vill., Torricelli Mts., 30.xi-8.xii.1958, W.W. Brandt, $1 \sigma$, BPBM; Wau, $1200 \mathrm{~m}$, 4-15.i.1965, J.H. Sedlacek, 1 \& , BPBM; same data, 21.ii.1965, J. \& M. Sedlacek, 1 \%; 19.i.1970, M. Sedlacek, 1 \&, both BPBM; Wau, 1200 m, 12-23.v.1965, H. Pyka, 1 \&, SMN; Wau, Morobe Dist., 18.x.1969, James E. Tobler, 1 ơ, 3 \& \&, CAS; same data but 20.x.1969, 2 \& ; 24.x.1969, 2 \%, all CAS; Wau, Morobe Dist., 1200 m 15-25.x.1961, J.H. Sedlacek, 1 o , BPBM; same data but J. Sedlacek, 1-20.xi.1961, 1 \&; 2.xii.1961, 2 ९ , all BPBM; 6.xii.1961, 1 \%; 15.v.1962, 1 \&, both ZMA; Wau, Big Wau Creek, Morobe Dist., $1200 \mathrm{~m}$, 26.vii.1972, Thomas W. Davies, $1 \propto, 1$ \%, CAS; same data but 12.ii.1973, $3 \circ \sigma, 2$ \% ९; 17.ii.1973, $3 \circ \sigma^{\circ}$; 5.iii.1973, $2 \sigma^{\circ} \circ$, 4 \% $\circ$, all CAS.

New Guinea (S.E.): Haveri, vii-xi.1893, Loria, $1 \sigma^{\circ}$, MSNG; Koitaki, 1500 ft., $x$-xi.1928, Pemberton, $1 \%, 4$ \% ९, BPBM; same data but xi-xii.1928, 1 \%, BPBM; Kokoda, $1200 \mathrm{ft}$., v.1933, L.E. Cheesman, ơ holotype Baeturia stylata, BMNH; same data but iv.1933, 1 \%; viii.1933, 1 \% allotype B. stylata; ix.1933, 1 \&; x.1933, 1 \& paratype Baeturia phyllophora Blöte, all BMNH; Paumomu River, ix-xii.1893, Loria, 1 o, 1 \&, MSNG; Popondetta, $60 \mathrm{~m}, 3-4 . i x .1963$, J. Sedlacek, $1 \sigma^{\circ}$, BPBM; same data but 1-4.ix.1963, 3 \% $\%$ BPBM; Poron, xi.1921, R. Neill, Rothschild bequest, $1 \sigma^{\circ}$, BMNH.

A strongly deviating specimen with locality label: "British New Guinea, 1921, R. Neill" and pasted in the corner of this label a second label: "Rothschild Bequest B.M. 1939-1." might belong to $G$. stylata or to a separate species. The specimen is not described as a separate species, since only one badly damaged male with insufficient locality information is available. Some remarks concerning this specimen are given at the end of this description. The specimen is in the BMNH.

N.B.: Blöte's allotype from the Endeavor River (Queensland) belongs to $G$. flava.

Remarks. - G. stylata is closely related to G. flava, sharing similarly fused claspers and a posteriorly directed aedeagus. The claspers of $G$. stylata however, have a distinct ventral protrusion. Males of $G$. stylata can further be separated from $G$. flava by the narrower gap between opercula and abdomen, a smaller protrusion on the lateral lobes of the pygofer, and an elongate eighth sternite. Females 
are very similar to those of $G$. flava; they can possibly be recognized by somewhat longer opercula. Furthermore, the hyaline border along the hind margin of the tegmen tends to be narrower than in G. flava.

Description. - Body ochraceous brown or partly greenish, probably entirely olive green when alive. Females of about the same size as males, but with more robust, broader head and thorax. Abdomen of males 1.2-1.4 times as long as head and thorax, of females 1.0-1.3 times as long. Male tegmen 1.2-1.3 times as long as body length, of females 1.2-1.4 times as long.

Head: Ochraceous, often reddish towards anterior margins of vertex lobes. Postclypeus angularly, and distinctly, protruding beyond vertex lobes; anterior margin angularly bent medially and angularly bending back at lateral corners, forming an almost
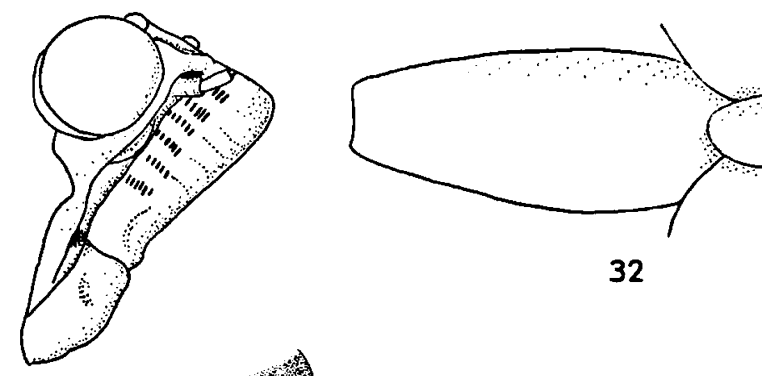

32

31

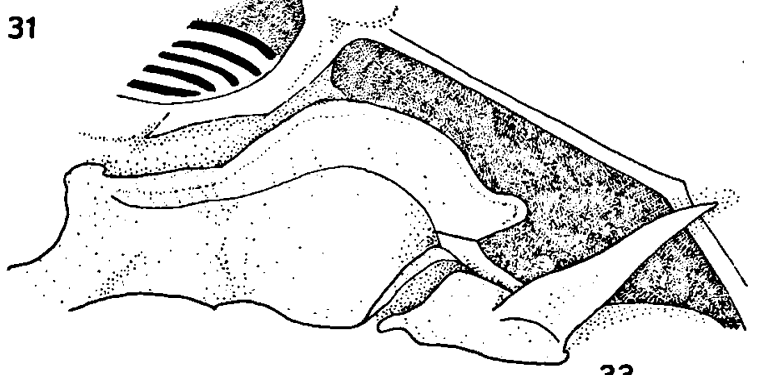

33

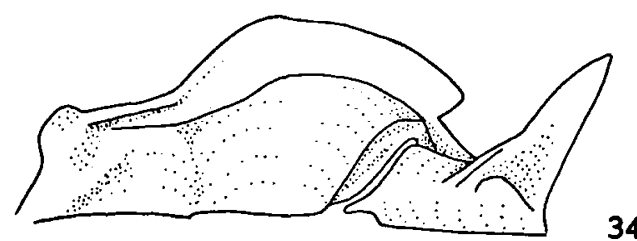

34

Figs. 31-34. Guineapsaltria stylata (Blöte, 1960), Umi River: 31, postclypeus in lateral view; 32, eighth sternite; 33, male operculum; 34, id., specimen with rectangular distomedial corner. right angle with anterior margins of vertex lobes (Fig. 4). Postclypeus not swollen, anterior margin (lateral view) slightly concave. Lateral sides of postclypeus quite smooth, but with about 5 or 6 indistinct rows of short parallel ridges (Fig. 31).

Tegmina: With fairly narrow hyaline border along hind margin, narrower than in G. flava.

Tymbal organ: Tymbal very small, extending over about $1 / 3$ of body width in lateral view. Five weakly sclerotized ridges spanning the tymbal from dorsal to ventral margin, a sixth most proximal ridge almost reaching ventral margin.

Opercula: Male operculum with distal part shorter than basal part, oblong-shaped and, in most specimens, narrowly elongate at distomedial corner (Fig. 33), but sometimes with rectangular distomedial corner (Fig. 34). Lateral margin straight, making an obtuse angle both with distal margin and with crest around lateral corner of basal part. Lateral part of this crest very short and knobby. Distal margin straight or slightly convex, but often strongly concave near rounded distomedial corner. Medial margin straight. Gap between operculum and abdomen quite narrow; operculum covering most of folded membrane in ventral view. Meracanthus reaching, or almost reaching, anterior margin of abdomen. Female operculum (Fig. 39) very similar to that of male, but rectangular, not elongate, at distomedial corner.

Abdomen: Uniformly ochraceous or greenish. First tergite of male very short, medially almost completely hidden under metanotum. Sternite 8 (Fig. 32) strongly elongate, reaching to about halflength of clasper. Female caudodorsal beak in dorsal view (Fig. 38) slender, rounded at apex.

Male genitalia: Pygofer in lateral view as in Fig. 37. Dorsal margin weakly convex, but at distal end concavely bent into slender and straight caudodorsal beak. Distal margin strongly convex, curving concavely into margin of beak. Ventral margin straight in lateral view, but strongly convex seen from behind (Fig. 43); ventral part of pygofer strongly pressed inward towards ventral margin. Basal part of pygofer opening very slender. Caudodorsal beak in dorsal view (Fig. 36) broad and short, bluntly rounded at apex. Lateral lobe of pygofer almost globularly rounded, curving in- 
wards towards distal margin. Lateral lobe with elongate, slender and distinctly posteriorly protruding knobby protuberance. Claspers (Fig. 35) parallel, extremely long, reaching far beyond pygofer margin, gradually curving downwards towards narrowly rounded apices. Clasper with broad triangular, and laterally flattened, ventral protrusion, rectangular at its apex. Apical part of clasper slender, with weak ventral hollow. Proximal half of claspers forming a shaft around aedeagus; claspers fused dorsally, between aedeagus and anal valves, and sharply curving upwards, forming a broad and ring-shaped collar around base of anal valves. Aedeagus directed posteriad, between, and parallel to, claspers, variable in length, often reaching well beyond clasper apex. Aedeagus (Fig. 41) long and slender, almost straight, but angularly bent down near apex, with extremely slender lateral crests and a pair of dorsal crests. The distinct angular and slender subapical lobe seems not connected with the lateral crests, and is slightly incised medially (Fig. 40). Aedeagus incised at apex (Fig. 42).

N.B.: One male from the Umi River differs greatly from the other specimens in genitalic structure. Its pygofer is characterized by extremely long, slender, and dorsally flattened protuberances on the lateral lobes (Fig. 45). These protuberances slightly curve inwards towards their apices. The caudodorsal beak is triangle-shaped in dorsal view and pointed at the apex. The clasper is very similar to that of the other specimens of $G$. stylata, but has a rounded, finger-shaped, and slightly posteriorly curved ventral protrusion (Fig. 44). The apical part of the clasper has a more distinct and laterally curving hollow. The aedeagus has a very small subapical lobe. The great similarity in clasper shape places this specimen in, or very close to, G. stylata. Whether this specimen should be regarded as a separate species or merely an aberration is not clear, though the fact that only one specimen was found, belonging to a larger series of $G$. stylata specimens, suggests the latter.

Measurements. - Body length 0 : 11.4-14.5 mm (mean 13.8 $\mathrm{mm} \pm 0.4)$, $:$ : 10.9-14.7 $\mathrm{mm}$ (mean $13.5 \mathrm{~mm} \pm 1.0)$; tegmen length ơ: 14.9-17.8 $\mathrm{mm}$ (mean $16.8 \mathrm{~mm} \pm 0.6$ ), $\$: 15.0-19.2$ $\mathrm{mm}$ (mean $17.8 \mathrm{~mm} \pm 1.2$ ); head length $\sigma: 1.0-1.4 \mathrm{~mm}$ (mean $1.3 \mathrm{~mm}$ ), $\%$ : $1.1-1.5 \mathrm{~mm}$ (mean $1.4 \mathrm{~mm}$ ); pronotum length $\sigma$ :

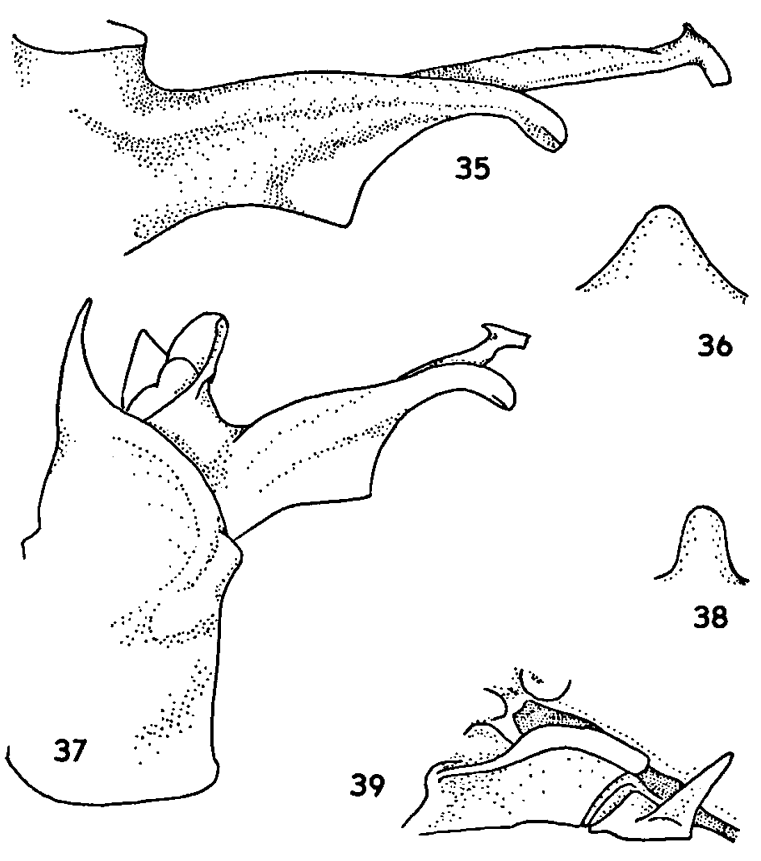

Figs. 35-39. Guineapsaltria stylata (Blöte, 1960), Umi River: 35, clasper; 36, male caudodorsal beak in dorsal view; 37 , pygofer in lateral view; 38 , female caudodorsal beak in dorsal view; 39 , female operculum.
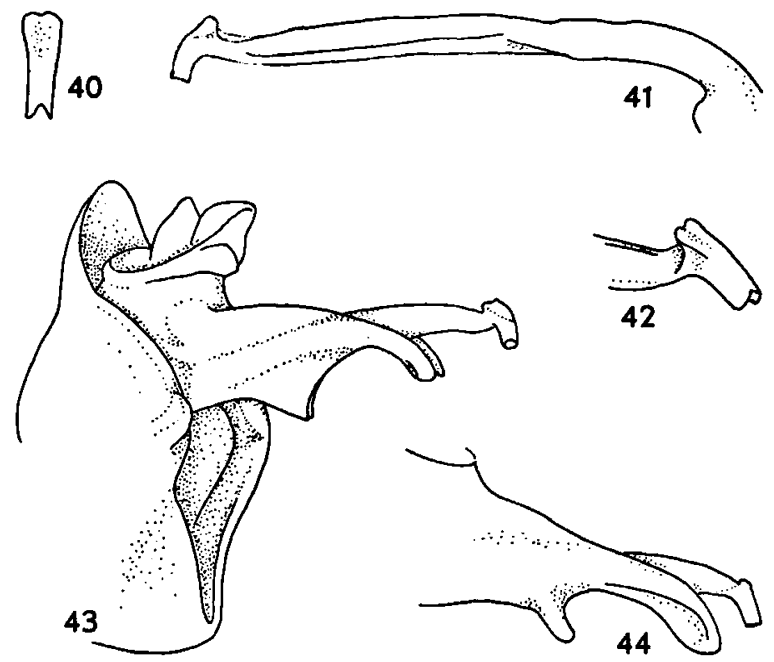

Figs. 40-44. Guineapsaltria stylata (Blöte, 1960), Umi River: 40, apex of aedeagus from above; 41 , aedeagus in lateral view; 42 , detail apex of aedeagus; 43 , pygofer from aslant; 44 , aberrant clasper.

1.1-1.6 mm (mean 1.4 mm), ९: 1.4-1.8 mm (mean $1.6 \mathrm{~mm}$ ); mesonotum length $\sigma: 2.2-3.4 \mathrm{~mm}$ (mean $3.0 \mathrm{~mm}$ ), $९: 2.5-3.7$ 


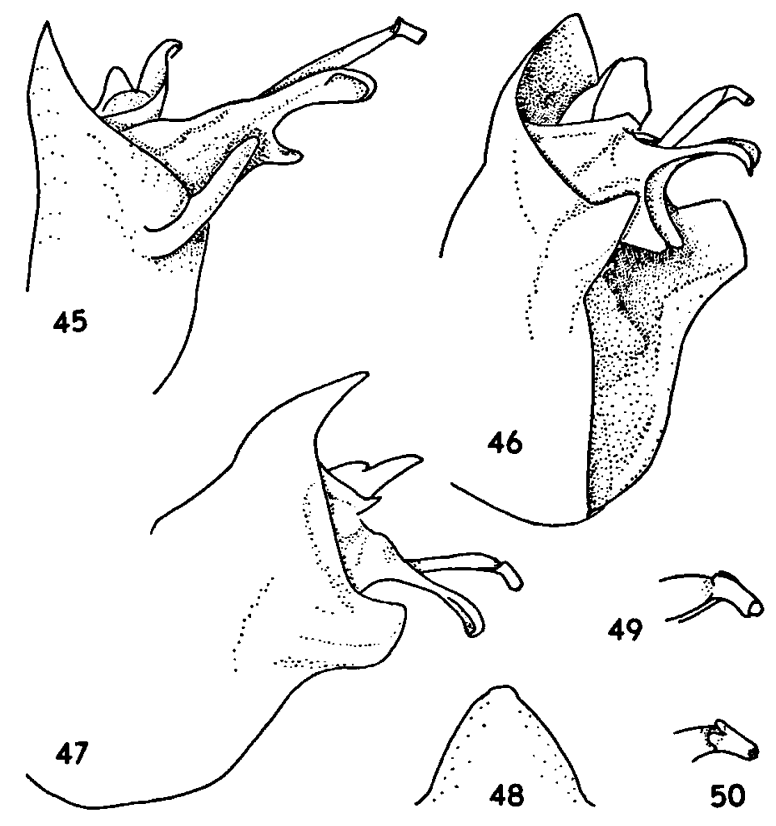

Figs. 45-50: 45, Guineapsaltria stylata (Blöte, 1960): aberrant pygofer in lateral view, Umi River. 46-50, Aberrant specimen British New Guinea: 46, pygofer from aslant; 47, pygofer in lateral view; 48 , male caudodorsal beak in dorsal view; 49 , detail apex of aedeagus from aslant; 50, id., from above.

mm (mean $3.4 \mathrm{~mm}$ ); head width ơ; $2.8-3.2 \mathrm{~mm}$ (mean 3.1 $\mathrm{mm}$ ), $९$ : 2.7-3.6 mm (mean $3.4 \mathrm{~mm}$ ); width of pronotal collar o : $3.6-4.2 \mathrm{~mm}$ (mean $4.0 \mathrm{~mm}$ ), $\$: 3.7-4.6 \mathrm{~mm}$ (mean 4.3 $\mathrm{mm})$.

Distribution (Fig. 2). - G. stylata is distributed throughout northern Papua New Guinea, including the Huon peninsula and the western half of the $\mathrm{Pa}$ puan peninsula, but is also recorded from Lake Archbold in the central mountain ranges of western New Guinea.

Note. - A male with locality label "British New Guinea" is presumably closely related to G. stylata, which is suggested by the angular ventral protrusion on its clasper (Fig. 46), but probably represents a different species, since it deviates strongly in other genital characters. The pygofer is characterized by a straight distal margin and large, angular and distinctly posteriorly projecting, laminiform protuberances on its lateral lobes (Fig. 47). Further- more, the pygofer is sharply edged and not pressed inwards at its ventral margin (Fig. 46). The specimen has a broad, triangular and apically truncate caudodorsal beak (Fig. 48) and the subapical lobes of its aedeagus (Figs. 49,50) are much smaller than in other specimens of $G$. stylata.

\section{Guineapsaltria viridula (Blöte, 1960) n. comb. (Figs. 3, 51-62)}

Baeturia viridula Blöte, 1960: 79, figs. 43-44; Duffels \& Van der Laan, 1985: 225.

Material examined. - Irian: New Guinea (W.): Dojo, iv.1958, G. den Hoed, o holotype Baeturia viridula, 1 \% paratype Baeturia viridula, RMNH; Hollandia, 22.ii.1952, L.D. Brongersma, 1 o , RMNH; Hollandia, 0-10 m, 17.x.1954, M. Boeseman, 1 \&, RMNH; Hollandia, xi.1957, G. den Hoed, 1 \&, RMNH; Hollandia Res., 10.i.1958, R.T. Simon Thomas leg., 1 ○ Baeturia viridula det. H.C. Blöte, 1 \% allotype Baeturia viridula. RMNH; Hollandia, 12.iv.1959, Neth. New Guinea Exped., 2 \& \&, RMNH; Hollandia-binnen, 100 m, 31.x.1958, J.L. Gressitt, 1 \% , BPBM; same data but 1.xi.1958, 1 \&, BPBM; Holl Maffen, 22 km E. of Sarmi, 18.vii.1959, T.C. Maa, $1 \sigma, 1$ \& , BPBM; Ifar, Cyclops Mts., 450-500 m, 8.ix.1962, J. Sedlacek, 4 ○ $\sigma^{\circ}, 1$ ९, BPBM; same data, 1 \% , ZMA; Maffin Bay, 3.viii.1944, E.S. Ross, 1 \&, CAS; Nabire, S. Geelvink Bay, 0-30 m, 2-9.vii.1962, J.L. Gressitt, 1 \%, 1 \%, BPBM; same data but J.L. Gressitt \& J. Sedlacek, $2 \circ \sigma, 3$ \& \& , BPBM; Nabire, S. Geelvink Bay, 1-20 m, 9.vii.1962, H. Holtman, 1 \%, BPBM; Pionierbivak, vi-vii.1920, W.C. v. Heurn, $1 \sigma^{\circ}$, MZB; Sentani, S.W. Cyclops, 100 m, 15.vi.1959, Gressitt \& Maa, 1 o , 1 \&, BPBM; Sentani W., Hollandia area, Cyclops Mts., 50-100 m, 22-24.vi.1959, J.L. Gressitt, 1 \&, BPBM.

Papua: New Guinea (N.E.): Neu Guinea, N.G. Companie, 2 ơ o, 1 \&, ZMB; Ambunti, Sepik River, 50 m, 6.v.1963, R. Straatman, 1 \&, BPBM; same data but 10.v.1963, 2 ९, BPBM; 150 m, 4.v.1963, 1 ơ, 2 \& \&, ZMA; 200 m, 7.v.1963, 2 \% ; $200 \mathrm{~m}, 9 . v .1963,1$ \%, all BPBM; Boana, $1000 \mathrm{~m}$, 22.xi.1965, H. Pyka, 1 \%, 3 \& \&, SMN; Bongu, K. Wilhelmland, A. Jacobi, 1 ơ, SMD; Bongu, K. Wilhelm-land, 1 \%, BMNH; Bulolo, 730 m, 31.vuii. 1956, E.J. Ford Jr., 1 \% , BPBM; Busu R., E. of Lae, $100 \mathrm{~m}, 14 . i x .1955$, J.L. Gressitt, $1 \sigma^{\circ}$, BPBM; Erima, Astrolabe Bay, 1896, Biró, $6 \circ \sigma, 12$ \% , TMB; Finschhafen, 20.iv.1944, E.S. Ross, 1 \& , CAS; same data but 29.iv.1944, 1 \&, CAS; 3.v.1944, 1 ơ, 1 \&, ZMA; 10.v.1944, 1 \%; 11.v.1944, 1 o; 15.v.1944, 1 ơ, 2 \& \&, all CAS; Kaindi, Mt. Morobe, 2350 m, 30.iv.1970, A.N. Gillogly \& S. Keenan, 1 o , BPBM; Lae, vii.1944, F.E. Skinner, 1 \%, BPBM; Lae, 1.v.1960, J. Mann, 1 ९, CAS; Lae, 1.v.1960, C.W. O'Brien, 1 o , 1 \%, BPBM; Lae, 30 m, 2.iv.1962, J. Sedlacek, 1 o, 1 \%, BPBM; same data, 1 o, 1 ९, ZMA; Lae, 18-24.i.1962, J. Sedlacek, 1 o, BPBM; Lae, Morobe Dist., 21.viii.1978, J.L. Gressitt, 1 o , BPBM; Lagoweng, $90 \mathrm{~m}$, 
15.x.1965, H. Pyka, 2 o o, 2 \%, SMN; Madang, $5 \mathrm{~m}$, 28.x.1958, J.L. Gressitt, 1 ○ , BPBM; Matuka, Madang, 0-100 m, 1.x.1968, N.L.H. Krauss, 1 o , BPBM; Oomsis, 22 mi. W. Lae on Lae-Bulolo road, $100 \mathrm{~m}, 26 . i v .1959$, Sixth Archbold Exped. to Papua New Guinea, L.J. Brass, 1 \&, AMNH; SumSum, 64 km N.Wau, 580 m, 15.ii.1963, H.W. Clissold, $1 \sigma$, BPBM; Umi River, Markham Valley, Morobe Distr., $480 \mathrm{~m}$, 18.xi.1959, Sixth Archbold Exped. to Papua New Guinea, L.J. Brass, $6 \sigma^{\circ} \sigma^{\circ}, 1$ \%, AMNH; same data but 20.xi.1959, $6 \sigma^{\circ} \sigma^{\circ}$, 4 \% \%, AMNH; same data, 1 ơ, 1 \%, ZMA; Wau, 1150-1200 m, 13.1.1966, J. Sedlacek, 1 \&, BPBM; Wau, $1200 \mathrm{~m}$, 21.xi.1963, J.L. Gressitt, 1 १, BPBM; same data but 30.xii.1964, J.L. Gressitt \& J. Sedlacek, 1 \&; 30.xii.1964, L. \& M. Gressitt, 1 \&; 3-7.iv.1964, J. Sedlacek, $2 \sigma^{\prime} \sigma^{\circ} ; 2$ 2.xii.1964, J. \& M. Sedlacek, 1 \&; 4-15.i.1965, J.H. Sedlacek, 1 \&; 4-15.i.1965, M. Sedlacek, 1 ơ; 15.x.1965, J. Sedlacek, 1 \%; 14.iii.1966, Gressitt \& Wilkes, 1 o'; xii.1967, J. \& M. Sedlacek, 1 o; 20.iii.1968, M. Sedlacek, 1 o , all BPBM; Wau, Big Wau Creek, 1100 m, 29.xi-30.xii.1964, Shanahan, 1 \&, BPBM; Wau, Big Wau Creek, Morobe Distr., 1200 m, 12.ii.1973, Thomas W. Davies, $1 \propto \sigma, 3$ $\%$, CAS; same data but 17.ii.1973, 1 o , 4 \% \%, CAS; same data, 1 \% , 1 \%, ZMA; S.iii.1973, 3 १ , CAS; Wau, Bulolo River, 850-950 m, 4.ii.1966, 1 \%, ZMA; Wau, Coivak Rdg., 763 m, 7.xii.1963, H.C., 1 \&, ZMA; Wau, Ecology Inst., Morobe Dist., 26.xii.1973, K.P. Lamb, 1 १, UPNG; Wau, Ecology Inst. Morobe Prov., 14.xii.1981, D. Black, $1 \sigma^{\circ}$, UPNG; Wau, Hospital Creek, 1200 m, 18.i.1965, J. Sedlacek, $1 \sigma^{\circ}$, BPBM; Wau, Morobe Dist., $1200 \mathrm{~m}$, 15-25.x.1961, J. Sedlacek, 1 ९, BPBM; same data but 1-20.xi.1961, J. \& J.H. Sedlacek, 2 १ \& ; 2-10.xi.1961, J. \& M. Sedlacek, 1 o ; 2.xii.1961, J. Sedlacek, 2 \& \%; 3.xii.1961, J. \& M. Sedlacek, 1 \%; 15.v.1962, J. Sedlacek, 2 $\% ; 25 . x i i .1962$, J. Sedlacek, 1 \&; 26.xii.1962, J. Sedlacek, 1 ơ; 8-10.i.1963, J. Sedlacek, 1 \%; 11.i.1963, J. Sedlacek, 1 \%, all BPBM; Wau, Morobe Dist., $1250 \mathrm{~m}, 11 . i .1963$, J. Sedlacek, 1 ơ, BPBM; same data but $1200-1300 \mathrm{~m}, 14 . i i .1963,1$ \%; $1300 \mathrm{~m}$, 28.i.1963, 1 \&, both BPBM; Wau, Morobe Dist., 2122.x.1969, James E. Tobler, 1 \%, CAS.

Bismarck Archipelago: New Britain: Gaulim, Gazelle Pen., 140 m, 19-20.xi.1962, J. Sedlacek, 1 o , BPBM; Illugi, Upper Warangoi, Gazelle Pen., 12-15.xii.1962, J. Sedlacek, $1 \propto$, BPBM; same data but 15.xii.1962, $1 \sigma^{\circ}$, BPBM; Talliligap, Gazelle Pen., 300 m, 17-18.xii.1962, J. Sedlacek, 1 \& , BPBM; Upper Warangoi, Gazelle Pen., 1250 m, 1-4.xii.1962, J. Sedlacek, 1 \%, BPBM.

Umboi Island: Awelkom 1 km N., 600 m, 21-28.ii.1967, G.A. Samuelson, 2 \% $\circ$, BPBM.

Manus Island: Manus ins., 14.i.1966, H. Pyka, 2 o $\sigma$, SMN. Note: Material from the Neu Guinea Companie was probably collected by Richard Rohde, v.1888, at Finschhafen (pers. comm. Dr. J. Deckert, Berlin).

Remarks. - G. viridula is the largest species of this genus, distinctly larger than the foregoing species, but also more robust, with a relatively broader head and thorax. G. viridula can be recognized by its diverging claspers.

Description. - Body ochraceous to light brown. Females of about same size as males, but with more robust, on average slightly broader head and thorax. Abdomen of males 1.1-1.4 times as long as head and thorax, of females 1.0-1.1 times as long. Male tegmen 1.2-1.3 times as long as body length, of females 1.3-1.4 times as long.

Head: Ochraceous, postclypeus sometimes slightly darkened. Postclypeus smoothly rounded at frontal edge, with broadly convex anterior margin. Anterior margin of postclypeus continuous, or nearly continuous, with anterior margins of vertex lobes (Fig. 51). Postclypeus slightly swollen, anterior margin (lateral view) slightly convex. Lateral sides of postclypeus with 4 or 5 shallow furrows and
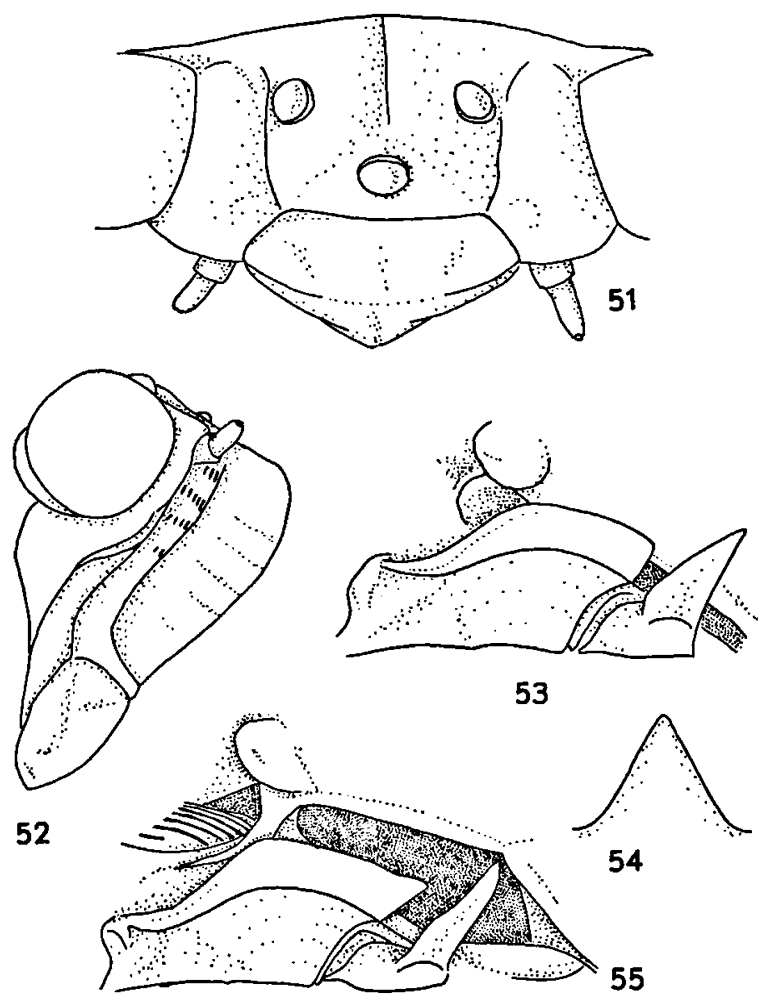

Figs. 51-55. Guineapsaltria viridula (Blöte, 1960): 51, head in dorsal view, Maffin Bay; 52, postclypeus in lateral view, Maffin Bay; 53, female operculum, Umi River; 54, female caudodorsal beak in dorsal view, Umi River; 55, male operculum, Umi River. 
about 6 or 7 short rows of short parallel ridges, generally restricted to a distinctly swollen crest along lorum (Fig. 52).

Tegmina: As in G. flava, with broad hyaline border along hind margin.

Tymbal organ: Six sclerotized ridges spanning the tymbal from dorsal to ventral margin, a seventh ridge almost reaching ventral margin and often an eighth, most proximal ridge, reaching to half the tymbal width. Seven short well-developed intercalary ridges.

Opercula: Male operculum (Fig. 55) with distal part shorter than basal part and oblong-shaped. Lateral margin straight, either rounded at distolateral corner or making an obtuse angle both with distal margin, and with crest around lateral corner of basal part. Distal margin straight or slightly convex, but sometimes slightly concave near the almost rectangular distomedial corner (cf. Fig. 33). Medial margin straight. Gap between operculum and abdomen quite narrow; operculum covering most of folded membrane in ventral view. Meracanthus just reaching to anterior margin of abdomen. Female operculum (Fig. 53) very similar to that of male, with straight margins and almost rectangular corners. Distal margin sometimes weakly concave towards distomedial corner. In some specimens distal part of operculum more trapezoid-shaped, with obtuse corners.

Abdomen: Unicolorous ochraceous or greenish, sometimes with reddish segmental hind margins. Male abdomen sometimes with traces of darkened lateroventral spots. First tergite of male very short, medially often completely hidden under metanotum. Female caudodorsal beak in dorsal view (Fig. 54) short and broad, triangle-shaped and sharply pointed at apex.

Male genitalia: Pygofer in lateral view as in Fig. 58. Dorsal margin short and straight, angularly bent upwards into stout and convex caudodorsal beak. Distal margin straight, making an obtuse angle with margin of beak. Ventral margin straight. Basal part of pygofer slightly curving inwards near base of pygofer opening, but not as distinctly as in G. stylata (Fig. 56). Caudodorsal beak in dorsal view (Fig. 59) broad and short, bluntly rounded at apex. Lateral lobe of pygofer almost globularly rounded, curving inwards towards distal margin,

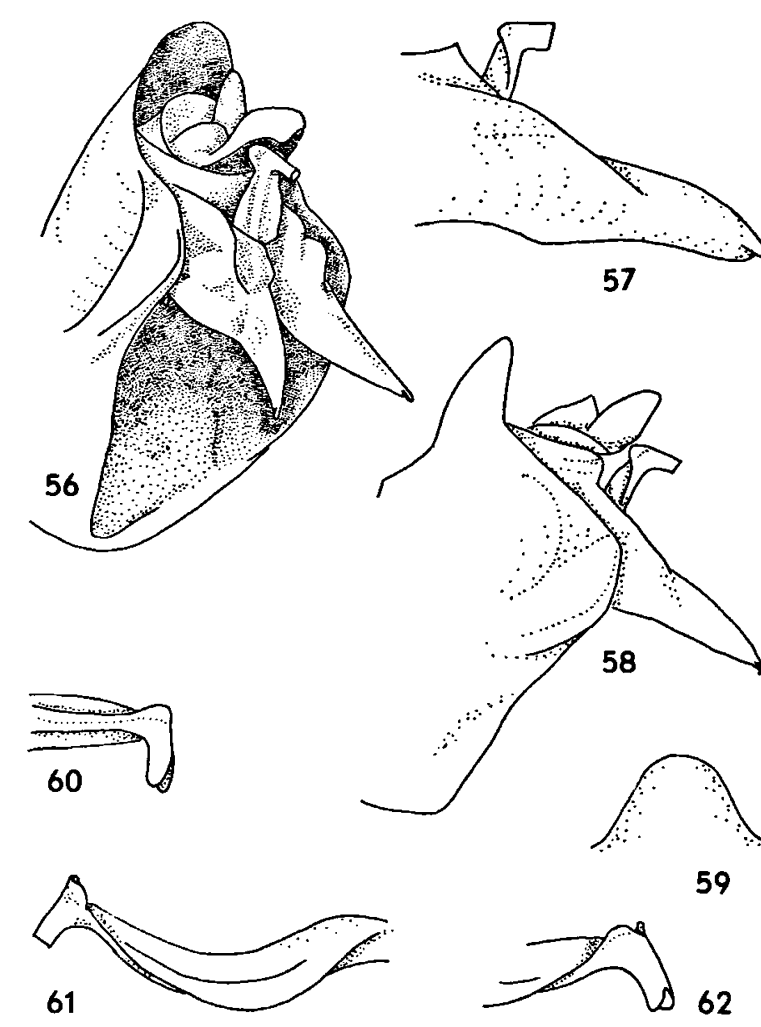

Figs. 56-62. Guineapsaltria viridula (Blöte, 1960), Umi River: 56 , pygofer from aslant; 57 , clasper; 58 , pygofer in lateral view; 59 , male caudodorsal beak in dorsal view; 60 , detail apex of aedeagus in lateral view; 61 , aedeagus in lateral view; 62 , apex of aedeagus from aslant.

often recurving at distal margin and sharply bending laterally towards ventral margin, forming a right angled broad and laminiform protuberance. Claspers (Fig. 57) long and straight, directed downwards parallel to distal margin of pygofer, strongly divergent, curving laterally, towards their apices (Fig. 56). Proximal part of clasper forming a slight dorsal crest around aedeagus. Clasper triangular in lateral view, swollen laterad, almost conical in shape, especially in its proximal half. Medial side of clasper flat, but swollen in front of aedeagus, supporting aedeagus in upright position. Clasper sharply pointed, thorn-shaped at apex, with very small ventral hollow. Claspers fused at base, forming a ring-shaped collar around base of anal valves. Aedeagus passing between proximal parts of claspers, adjacent to base of anal valves. Aedeagus (Fig. 61) strongly upcurved, but bent down at 
almost right angle near apex; with very broad and strongly laterally protruding crests. These crests bend upwards at distal ends and amplify into small, recurving subapical lobes at bending point of aedeagus (Figs. 60, 62). These lobes often partly fused to form single collar. Apex of aedeagus distinctly incised (Fig. 62).

Measurements. - Body length $\sigma:$ 15.0-17.0 mm (mean 16.0 $\mathrm{mm} \pm 0.5$ ), $9: 13.3-16.8 \mathrm{~mm}$ (mean $15.3 \mathrm{~mm} \pm 0.9$ ); tegmen length $\sigma^{\circ}: 18.8-21.5 \mathrm{~mm}$ (mean $20.1 \mathrm{~mm} \pm 0.8$ ), $९: 18.5-22.2$ $\mathrm{mm}$ (mean $20.3 \mathrm{~mm} \pm 1.3$ ); head length $\sigma^{\circ}: 1.3-1.7 \mathrm{~mm}$ (mean $1.5 \mathrm{~mm}$ ), $९$ : $1.4-1.7 \mathrm{~mm}$ (mean $1.5 \mathrm{~mm}$ ); pronotum length $\sigma$ : 1.8-2.1 mm (mean 1.9 mm), $\odot: 1.7-2.2 \mathrm{~mm}$ (mean $2.0 \mathrm{~mm}$ ); mesonotum length $\sigma^{\circ}: 3.3-4.0 \mathrm{~mm}$ (mean $3.7 \mathrm{~mm}$ ), $\%: 3.4-4.4$ mm (mean $3.8 \mathrm{~mm}$ ); head width o': $3.6-4.0 \mathrm{~mm}$ (mean 3.8 $\mathrm{mm}$ ), $8: 3.4-4.2 \mathrm{~mm}$ (mean $3.9 \mathrm{~mm}$ ); width of pronotal collar ơ: 4.5-5.0 mm (mean $4.8 \mathrm{~mm}$ ), $\%: 4.5-5.5 \mathrm{~mm}$ (mean 5.0 $\mathrm{mm})$.

Distribution (Fig. 3). - G. viridula is widely distributed along the northern mountain ranges of New Guinea, including the Huon peninsula and the northwestern part of the Papuan peninsula. The species is also recorded from Umboi Island, the Gazelle peninsula of New Britain and Manus Island of the Admiralty Islands.

Guineapsaltria chinai (Blöte, 1960) n. comb. (Figs. 3, 63-72)

Baeturia chinai Blöte, 1960: 75, Figs. 30-31; Duffels \& Van der Laan, 1985: 252.

Material examined. - Papua: New Guinea (S.E.): Mt. Astrolabe, ii.1893, Loria, $1 \sigma^{\circ}, 1$ \%, MSNG; Bome, Goilala, Owen Stanley Range, 1950 m, 16-30.iv.1958, W.W. Brandt, 2 ㅇ , BPBM; Konobosea, Port Moresby, 30.1.1965, J. Johnson, 1 \& , UPNG; Loloipa, Goilala, Owen Stanley Range, 25.xi-10.xii.1957, W.W. Brandt, $1 \sigma, 2 \% \%$, BPBM; same data but 11-20.xii.1957, 1 \%, 2 \& \& BPBM; 1 \%, 1 \%, ZMA; 21-31.xii.1957, 1 \%, 3 ९ \% 16-30.i.1958, 3 ○ $\sigma^{\circ}, 5$ ९ ; 1-15.ii.1958, 1 \&, all BPBM; Port Moresby area, v.1947, L. Jones, $\sigma$ holotype Baeturia chinai, $\$$ allotype Baeturia chinai, BMNH; Tapini, Central Dist., 800-1000 m, xi.1968, N.L.H. Krauss, 1 o , BPBM; Tapini, Goilala, Owen Stanley Range, 975 m, 16-25.xi.1957, 2 \% $\sigma^{\circ} 1$ \%, BPBM.

Remarks. - G. chinai certainly belongs to this genus, but rather strongly deviates from the other species. The aedeagus of $G$. chinai is not bent down towards its apex and, though it has a very large subapical protrusion, this protrusion is very different (globularly swollen) from those of other species of the genus. Furthermore, the lateral ocelli are more closely together in $G$. chinai than in other species of Guineapsaltria, though the distance between the lateral ocelli, compared to the width of the frontal ocellus, tends to be still larger than in related species groups. $G$. chinai is closely related to $G$. viridula, sharing a very similar clasper. Males of $G$. chinai are easily recognized by the peculiar aedeagus, the smooth and broad collar around the base of the anal valves and the long medial margins of the opercula. Females can be recognized by their very short and sickle-shaped opercula.

Description. - Body ochraceous brown, tinged with red, especially in the females. Male abdomen with reddish segmental hind margins; several specimens with a lateroventral row of slightly darkened spots. Females smaller than males, but with more robust head and thorax. Abdomen of males 1.4-1.6 times as long as head and thorax, of females 1.0-1.2 times as long. Male tegmen 1.2 times as long as body length, of females 1.3-1.4 times as long.

Head: Reddish brown, vertex and postclypeus with short red-brown hairs. Postclypeus broad, oblong-shaped, anterior margin weakly convex and, as in $G$. stylata, distinctly protruding beyond vertex lobes. Anterior margin of postclypeus angularly bending back at lateral corners, forming almost right angle with anterior margins of vertex lobes. Postclypeus not swollen, anterior margin (lateral view) slightly concave. Lateral sides of postclypeus quite smooth, with about 4 shallow furrows and 6 or 7 short rows of short parallel ridges forming a broad, but not inflated band along lorum (Fig. 63).

Tegmina: With very broad hyaline border along hind margin, broader than in other species of Guineapsaltria.

Tymbal organ: Tymbal very large, in lateral view extending over almost half of body width. Five weakly sclerotized ridges spanning the tymbal from dorsal to ventral margin, and a sixth, most proximal, ridge almost reaching ventral margin. Five 

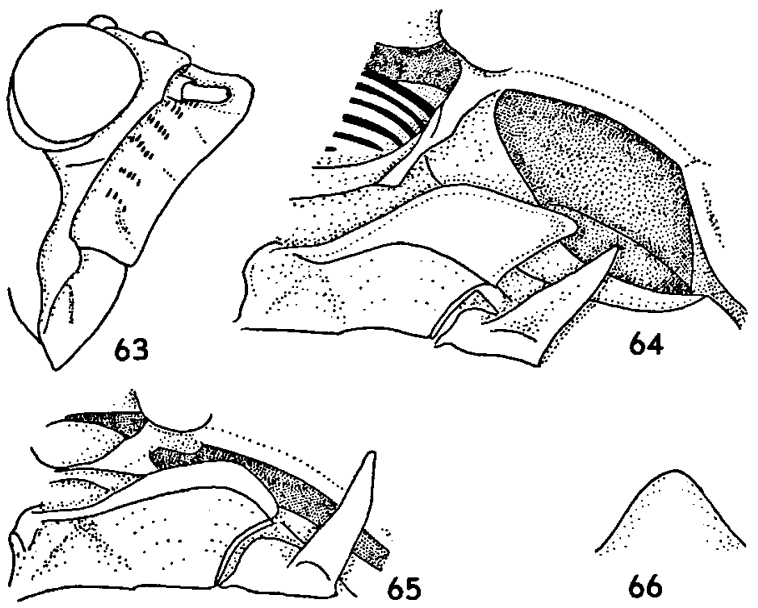

66

Figs. 63-66. Guineapsaltria chinai (Blöte, 1960), Loloipa: 63, postclypeus in lateral view; 64, male operculum; 65, female operculum; 66, female caudodorsal beak in dorsal view.
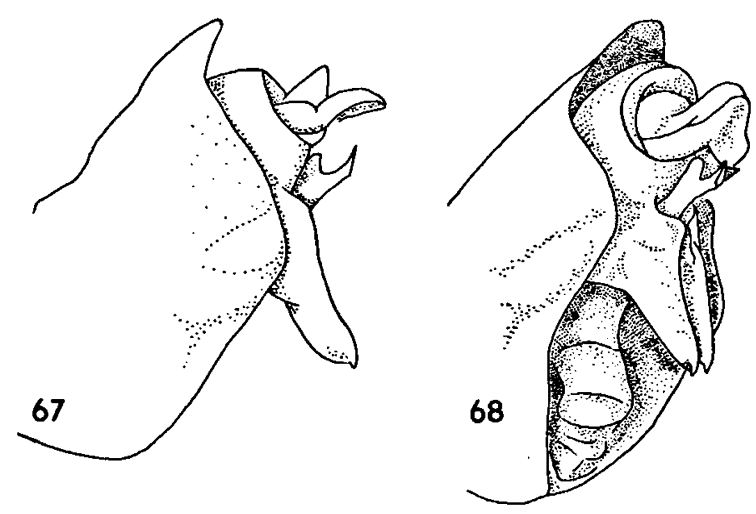

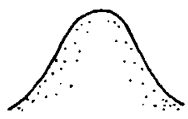

69

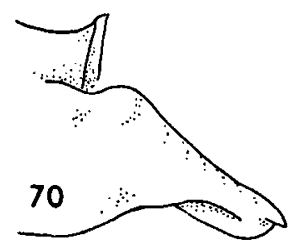

Figs. 67-72. Guineapsaltria chinai (Blöte, 1960), Loloipa: 67, pygofer in lateral view; 68, pygofer from aslant; 69, male caudodorsal beak in dorsal view; 70 , clasper; 71 , detail apex of aedeagus; 72, aedeagus in lateral view.

distinct intercalary ridges seem to form a band across tymbal.

Opercula: Male operculum (Fig. 64) with the dis- tal part almost triangle-shaped and, at its very long and straight medial margin, longer than the basal part. Lateral margin straight or slightly convex, making an obtuse and rounded angle with distal margin, and with crest around distolateral corner of basal part. Distal margin straight, slightly directed posteriad. Distomedial corner narrowly rounded. Gap between operculum and abdomen very wide; folded membrane almost completely visible. Meracanthus reaching just beyond distomedial corner of operculum. Female operculum (Fig. 65) extremely short and sickle-shaped. Distal part hardly more than a continuation of the crest around distolateral corner of basal part.

Abdomen: Male abdomen light ochraceous and slightly inflated. First tergite completely visible medially. Female caudodorsal beak in dorsal view (Fig. 66) short, bluntly rounded at apex.

Male genitalia: Pygofer in lateral view as in Fig. 67. Dorsal margin almost straight, concave near pygofer base and concavely bent at base of short, and stout caudodorsal beak. Distal margin straight, in most specimens making an obtuse angle with margin of beak, in others more gradually curving into margin of beak. Ventral margin straight. Pygofer opening fairly broad (Fig. 68). Caudodorsal beak in dorsal view (Fig. 69) short and bluntly rounded at apex. Lateral lobe of pygofer slightly curving inwards towards distal margin, but sharply folding back at end of distal margin, forming a broad, bluntly rounded and slightly swollen protuberance. Claspers closely resembling those of $G$. viridula, long and straight, directed downwards along distal margin of pygofer, and parallel to their apices. Clasper (Fig. 70) triangular in lateral view, distinctly swollen laterally and sharply pointed, thorn-shaped, at apex. Dorsal margin of clasper concave in lateral view, but convex near apex and angularly bent near clasper base, forming a small crest with inwards curving corner around aedeagus. Clasper base forming a high and smoothly rounded collar around base of anal valves, sharply indented mid-between claspers, opposite aedeagus. Aedeagus passing between proximal parts of claspers, adjacent to base of anal valves, almost straight, slightly upcurved and pointed at apex. Aedeagus pore almost oval-shaped, but pointed at apex of aedeagus (Fig. 71). Aedeagus with short, but very 
broad lateral crests and a large, bluntly rounded, but laterally flattened, subapical protuberance (Fig. 72). This protuberance is continuous with a short dorsal crest, but not connected to the lateral crests.

Measurements. - Body length $\sigma^{\circ}: 14.2-16.1 \mathrm{~mm}$ (mean 15.3 $\mathrm{mm} \pm 0.7$ ), $९: 12.2-14.5 \mathrm{~mm}$ (mean $13.4 \mathrm{~mm} \pm 0.9$ ); tegmen length $\sigma^{*}: 16.7-19.0 \mathrm{~mm}$ (mean $18.1 \mathrm{~mm} \pm 0.7$ ), $९: 16.2-19.8$ $\mathrm{mm}$ (mean $18.2 \mathrm{~mm} \pm 0.9$ ); head length $\sigma: 1.2-1.4 \mathrm{~mm}$ (mean $1.3 \mathrm{~mm}$ ), $९: 1.2-1.5 \mathrm{~mm}$ (mean $1.4 \mathrm{~mm}$ ); pronotum length $\sigma$ : $1.5-1.7 \mathrm{~mm}$ (mean $1.6 \mathrm{~mm}$ ), $ᄋ: 1.5-1.8 \mathrm{~mm}$ (mean $1.7 \mathrm{~mm}$ ); mesonotum length $\sigma^{\circ}: 2.8-3.3 \mathrm{~mm}$ (mean $3.0 \mathrm{~mm}$ ),,$: 2.6-3.5$ mm (mean $3.1 \mathrm{~mm}$ ); head width $\sigma^{\circ}: 3.1-3.4 \mathrm{~mm}$ (mean 3.2 $\mathrm{mm}$ ), $\$: 3.2-3.5 \mathrm{~mm}$ (mean $3.3 \mathrm{~mm}$ ); width of pronotal collar o : $3.8-4.5 \mathrm{~mm}$ (mean $4.1 \mathrm{~mm}$ ), $९$ : $3.7-4.6 \mathrm{~mm}$ (mean 4.3 $\mathrm{mm})$.

Distribution (Fig. 3). - G. chinai is probably endemic to the Papuan peninsula.

Guineapsaltria pallida (Blöte, 1960) n. comb.

(Figs. 3, 73-84)

Baeturia pallida Blöte, 1960: 76, fig. 35; Duffels \& Van der Laan, 1985: 254.

Material examined. - Irian: New Guinea (W.): Bernhard Camp B., 100 m, 9.iv.1939, L.J. Toxopeus, Neth. Ind. - American New Guinea Exped., 1 \& , RMNH; Bewani Mts., Humboldt Bay Dist., 400 m, vii.1937, W. Stüber, 1 o , BMNH; Bodem, Sarmi area, 10.vii.1959, T.C. Maa, $1 \sigma^{\circ}$, BPBM; Hollandia, $140^{\circ} \mathrm{E}$ $3^{\circ} 10^{\prime} \mathrm{S}, 300-600 \mathrm{~m}$, i.1937-8, W. Stüber, 1 \% , 3 \% \&, BMNH; Sabron, Cyclops Mts., Camp 1, 15.v.1936, L.E. Cheesman, 1 १, BMNH; Waris, S. of Hollandia, 450-500 m, 1-2.viii.1959, T.C. Maa, 1 ơ, BPBM; same data but 1-7.viii.1959, 1 \&; 8-15.viii.1959, $1 \propto, 1$ \%, all BPBM.

Papua: New Guinea (N.E.): Baiteta, $12 \mathrm{~km} \mathrm{N.W.} \mathrm{Alex-}$ ishafen, Madang Province, $5^{\circ} 00^{\prime} \mathrm{S} 145^{\circ} 45^{\prime} \mathrm{E}, 17$. iii.1987, Norman D. Penny, 1 \&, CAS; Maprik, 16.x.1957, J. Smart, o holotype Baeturia pallida, BMNH; Matoko, Saidor, Finisterre Range, 28.viii-5.ix.1958, W.W. Brandt, 1 \%, 1 \&, ZMA; Mokai Vill., Torricelli Mts., $750 \mathrm{~m}, 8-15 . x i i .1958$, W.W. Brandt, 1 \%, 1 \&, BPBM; same data but 16-31.xii.1958, $1 \sigma^{\circ}$, BPBM; Sapi Forrest reserve, $30 \mathrm{~km}$ W. Madang, Madang Province, $5^{\circ} 12^{\prime} \mathrm{S} 145^{\circ} 30^{\prime} \mathrm{E}, 20 . \mathrm{iii} .1987$, Norman D. Penny, 1 \%, CAS.

Remarks. - G. pallida closely resembles $G$. viridula but has parallel and more posteriorly directed claspers, similar to those seen in G. chinai. G. palli- $d a$ is distinctly smaller than G. viridula or G. chinai, and has a quite different aedeagus.

Description. - Body pale yellowish brown. Females on average slightly larger than males. Abdomen of males 1.2-1.4 times as long as head and thorax, of females 1.0-1.3 times as long. Tegmina of males and females 1.2-1.4 times as long as body length.

Head: Ochraceous. Postclypeus, as in G. viridu$l a$, smoothly rounded at anterior edge and with broadly convex anterior margin. Anterior margin of postclypeus continuous, or nearly continuous, with anterior margins of vertex lobes. Postclypeus slightly swollen, anterior margin (lateral view) slightly convex. Lateral sides of postclypeus very smooth, with about 3 weak ridges and an inflated crest along lorum. Some specimens have several weak and irregular rows of short parallel ridges on this crest, but in most specimens the crest is smoothly rounded (Fig. 73).
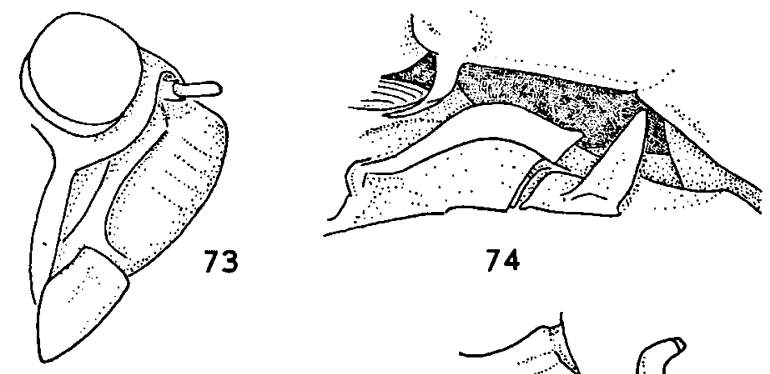

74
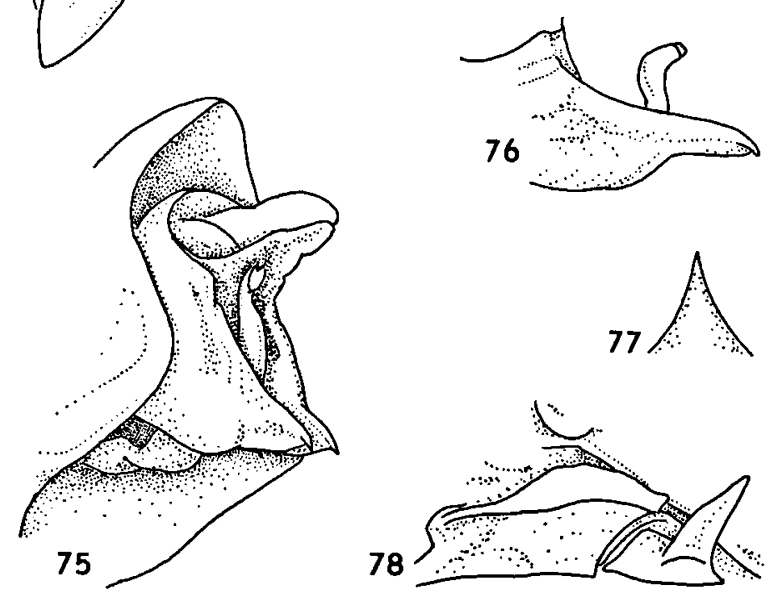

Figs. 73-78. Guineapsaltria pallida (Blöte, 1960): 73, postclypeus in lateral view, Mokai; 74, male operculum, Mokai; 75, pygofer from aslant, Mokai; 76 clasper, Bodem; 77, female caudodorsal beak in dorsal view, Matoko; 78, female operculum, Matoko. 


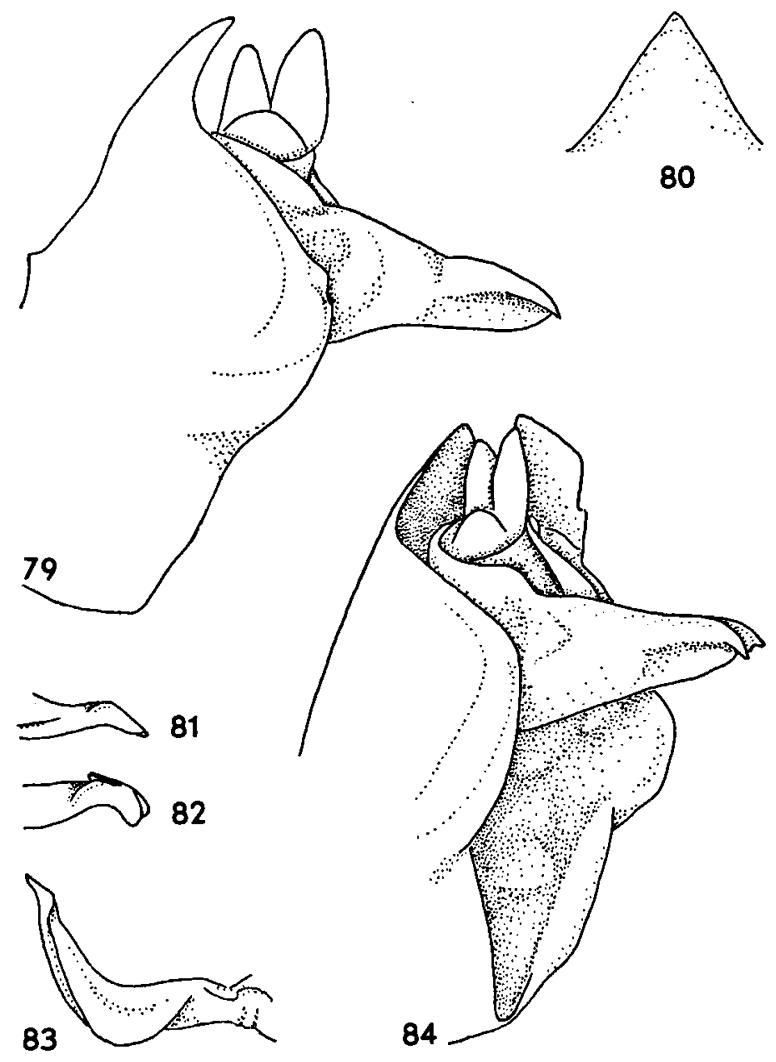

Figs. 79-84. Guineapsaltria pallida (Blöte, 1960): 79, pygofer in lateral view, Mokai; 80 , male caudodorsal beak in dorsal view, Mokai; 81, detail apex of aedeagus, Matoko; 82, id., Bodem; 83, aedeagus in lateral view, Mokai; 84, pygofer from aslant, Mokai.

Tegmina: The hyaline border along the hind margin of the tegmen is quite narrow as in G. stylata, narrower than in G. viridula.

Tymbal organ: Tymbal very small, as in G. styla$t a$, in lateral view extending over about $1 / 3$ of body width. Five sclerotized ridges spanning the tymbal from dorsal to ventral margin, a sixth ridge almost reaching ventral margin and often a seventh, most proximal, ridge reaching to half the tymbal width. Seven short intercalary ridges hardly visible.

Opercula: Male operculum (Fig. 74) with distal part distinctly shorter than basal part and slightly erect. Lateral margin straight, making an obtuse angle with long and straight crest around lateral corner of basal part. Distal margin straight, either concave near narrowly rounded distomedial corner, or straight to rectangular distomedial corner. Medial margin short and straight. Operculum partly cover- ing tymbal cavity in ventral view, folded membrane hardly visible in ventral view. Meracanthus often reaching beyond anterior margin of abdomen. Female operculum (Fig. 78) of similar shape, but shorter than that of male. Distal part oblongshaped, or trapezoid-shaped, with obtuse distomedial corner.

Abdomen: Male abdomen pale yellowish brown. First tergite very short and completely hidden under metanotum medially. Female abdomen often more reddish brown. Female caudodorsal beak in dorsal view (Fig. 77) short and slender, triangle-shaped and sharply pointed at apex.

Male genitalia: Pygofer in lateral view as in Fig. 79. Dorsal margin weakly concave, convexly bending into slender caudodorsal beak. Distal margin weakly convex, either concavely, or angularly bending into margin of caudodorsal beak. Ventral margin straight. Ventral margins converge to sharp angle at base of pygofer (Fig. 84). Caudodorsal beak in dorsal view (Fig. 80) broadly triangular, pointed at apex, but rounded in the Humboldt Bay specimen. Lateral lobe of pygofer almost globularly rounded, curving inwards towards distal margin, but sharply curving laterally towards ventral margin, forming a right angled broad laminiform protuberance. Claspers (Fig. 76) long and straight, triangular in lateral view, laterally swollen, to almost conical-shaped, especially in proximal half. Clasper sharply pointed, thorn-shaped at apex. Apical part of clasper laterally weakly indented, forming an elongate clasper hollow without sharp edges. Claspers fused at base, though not forming a distinct ring-shaped collar around base of anal valves. Aedeagus passing between claspers at about halflength of clasper and sharply recurving; its apex in some specimens hidden between anal valves (Fig. 75). Aedeagus (Fig. 83) strongly upcurved at halflength, and weakly recurving near apex, with very broad, strongly laterally protruding crests. These crests being broadest at basal curvature of aedeagus, curving upwards at their distal ends and amplifying very slightly to narrow recurving protuberances at apical bending point of aedeagus. Aedeagal apex in some specimens almost pointed in lateral view, with oval-shaped aedeagus pore (Fig. 81), in other specimens incised at apex (Fig. 82). 
Measurements. - Body length $\sigma$ : 11.8-13.8 mm (mean 12.6 $\mathrm{mm} \pm 0.6$ ), $\%: 11.0-13.6 \mathrm{~mm}$ (mean $12.6 \mathrm{~mm} \pm 0.9$ ); tegmen length $\sigma:$ : 14.4-17.3 mm (mean $16.3 \mathrm{~mm} \pm 0.8$ ), $\$: 14.9-17.8$ $\mathrm{mm}$ (mean $16.7 \mathrm{~mm} \pm 1.1$ ); head length $\sigma: 1.0-1.3 \mathrm{~mm}$ (mean $1.2 \mathrm{~mm}$ ), $\%: 1.2-1.4 \mathrm{~mm}$ (mean $1.3 \mathrm{~mm}$ ); pronotum length $\sigma^{\circ}$ : 1.4-1.5 mm, \&: $1.5-1.7 \mathrm{~mm}$ (mean $1.6 \mathrm{~mm}$ ); mesonotum length $\sigma^{\circ}: 2.5-3.1 \mathrm{~mm}$ (mean $2.8 \mathrm{~mm}$ ), $\wp: 2.6-3.7 \mathrm{~mm}$ (mean $3.1 \mathrm{~mm}$ ); head width ơ : 2.8-3.2 mm (mean $3.0 \mathrm{~mm}$ ), 3.0-3.3 mm (mean $3.2 \mathrm{~mm}$ ); width of pronotal collar $\sigma^{\circ}$ : 3.5-4.4 mm (mean $3.8 \mathrm{~mm}$ ), ㅇ: $3.7-4.3 \mathrm{~mm}$ (mean $4.0 \mathrm{~mm}$ ).

Distribution (Fig. 3). - G. pallida is widely distributed in the northern mountain ranges of New Guinea.

Note. - In the western part of the distribution area (Bodem, Hollandia), the apex of the aedeagus is truncate in lateral view and distinctly incised mesiad; in the eastern part (Finisterre, Torricelli), the apex is almost pointed, only slightly incised ventrally, and the pore is almost oval-shaped. Of the three male specimens from Waris, two have a truncate incised apex and one a pointed apex with oval pore.

Guineapsaltria pallidula n. sp.

(Figs. 3, 85-94)

Material examined. - Types: Holotype: "Hollandia / New Guinea / H. Hoogstraal" (print); "Rain forest / Elev. $250 \mathrm{ft} /$ May 1945" (print); "Property of / Entomology Dept. / North Carolina / State University" (print), ${ }^{\circ}$, NCSU. Paratypes: Ned. New Guinea, xi-10-1944, T. Aarons, 1 ơ, CAS; same data but $225 \mathrm{ft}, 20 . x .1944,1 \sigma^{\circ}$, ZMA; same data, 1 \&, CAS; Hollandia, 12.v.1938, L.J. Toxopeus, Neth. Ind. - American New Guinea Exped. 1938-39, 1 \%, RMNH.

Papua: New Guinea (N.E.): Bumayong, Lae, 4-8.ix.1965, H. Pyka, 2 ơ , SMN; Lagoweng, 90 m, 15.x.1965, H. Pyka, 9 o $\sigma^{\circ}, 3$ ९ , SMN; same data, 2 o $\sigma$, ZMA.

Remarks. - G. pallidula is very similar to G. palli$d a$, but tends to have shorter, more robustly swollen claspers, though the material from Bumayong and Lagoweng has more slender claspers, as in G. pallida. The species is easily recognized by the straight aedeagus with its pair of recurving subapical lobes. It can further be separated from $G$. pallida by its longer femoral spines.
Description. - Body pale yellowish brown. Females slightly larger than males. Abdomen of males 1.2-1.5 times as long as head and thorax, of females 1.1-1.3 times as long. Male tegmen 1.1-1.3 times as long as body length, of females 1.2-1.4 times as long.

Head: Ochraceous. Postclypeus rounded at anterior edge, with broadly convex anterior margin. Anterior margin of postclypeus continuous, or nearly continuous, with anterior margins of vertex lobes. Postclypeus slightly swollen, anterior margin (lateral view) slightly convex. Lateral sides of postclypeus very smooth, with about 4-5 weak ridges and, differing from $G$. pallida, with some irregular rows of short parallel ridges on inflated crest along lorum.

Tegmina: with broad hyaline border along hind margin, as broad as in G. pallida and G. viridula.

Legs: Fore femur with row of three very long spines. Proximal spine much longer than middle spine and longer than distance between proximal and middle spine.

Tymbal organ: Five sclerotized ridges spanning the tymbal from dorsal to ventral margin, a sixth ridge almost reaching ventral margin and often a seventh, most proximal, ridge reaching to half the tymbal width. Seven short intercalary ridges vaguely visible.

Opercula: Male operculum (Fig. 88) with very short and erect, oblong-shaped, distal part, less than $1 / 3$ as long as basal part. Lateral margin straight, making an obtuse angle with crest around lateral corner of basal part. Distal margin straight, making a right angle with short and straight medial margin. Distolateral corner rounded. Gap between operculum and abdomen quite narrow, but broader than in G. pallida; folded membrane clearly visible in ventral view. Meracanthus not reaching abdomen. Female operculum (Fig. 86) very similar to that of male; distal margin in one specimen making an obtuse, or right, angle with medial margin.

Abdomen: Male abdomen pale yellowish brown. First tergite very short and medially partly hidden under metanotum. Female abdomen often more reddish brown. Female caudodorsal beak in dorsal view (Fig. 85) short and narrow, triangle-shaped and sharply pointed at apex. 


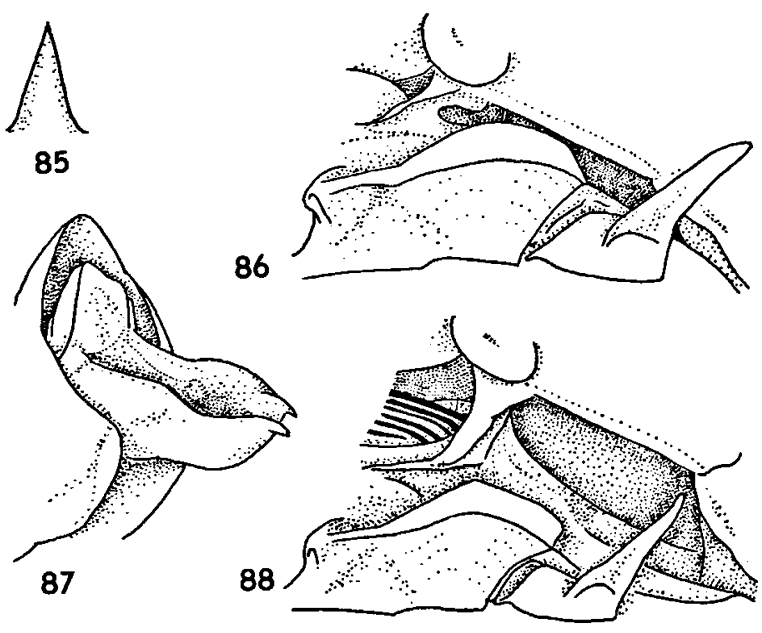

Figs. 85-88. Guineapsaltria pallidula n. sp., paratype: 85, female caudodorsal beak in dorsal view; 86 , female operculum; 87, pygofer and claspers from above; 88 , male operculum.

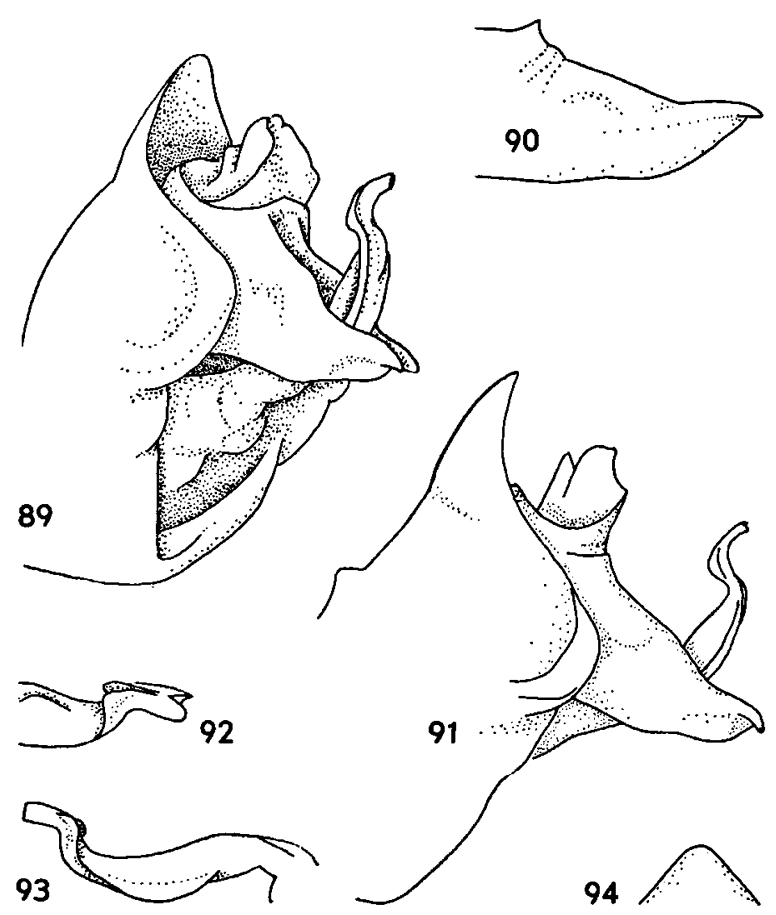

Figs. 89-94. Guineapsaltria pallidula n. sp.: 89, pygofer from aslant, holotype; 90, clasper, holotype; 91, pygofer in lateral view, holotype; 92, detail apex of aedeagus, Lagoweng; 93, aedeagus in lateral view, Lagoweng; 94, caudodorsal beak in dorsal view, holotype.

Male genitalia: Pygofer in lateral view as in Fig. 91. Dorsal margin straight, angularly bent upwards into stout and convex caudodorsal beak. Distal margin straight, concavely bent into margin of beak. Ventral margin almost straight. Ventral margins converge to a sharp angle at base of pygofer opening (Fig. 89). Caudodorsal beak in dorsal view (Fig. 94) broad and short, rounded, almost pointed at apex. Lateral lobe of pygofer almost globularly rounded, curving inwards towards distal margin, but sharply bending laterally towards ventral margin, forming a right-angled, broad and laminiform protuberance. Claspers (Fig. 90) short and broad towards apex, though more slender in material from Bumayong and Lagoweng. Clasper laterally swollen, almost conical-shaped, especially in proximal half, and sharply pointed, thorn-shaped, with a small ventral hollow, at apex. Proximal half of claspers fused to a gutter-shaped dorsal furrow between aedeagus and anal valves (Fig. 87). Apical part of aedeagus generally bending strongly back, resting in this furrow. Aedeagus generally passing between claspers close to clasper apex. Basal part of aedeagus in lateral view often visible below claspers (Fig. 91). Aedeagus (Fig. 93) slender and slightly curved in its proximal half, but strongly Z-shaped near apex, with long, slender lateral crests, short dorsal crests, and a midventral crest at base of $\mathbf{Z}$. The lateral crests curve upwards at distal ends and amplify to form a pair of recurving lobes at middle part of Z. Apex of aedeagus slightly incised (Fig. 92).

Measurements. - Body length $\sigma$ : 11.9-13.8 mm (mean 12.9 $\mathrm{mm} \pm 0.4$ ), $\$: 12.6-13.3 \mathrm{~mm}$ (mean $12.8 \mathrm{~mm} \pm 0.3$ ); tegmen length $\sigma^{\prime}: 14.3-17.0 \mathrm{~mm}$ (mean $15.3 \mathrm{~mm} \pm 0.8$ ), $\$: 16.4-17.5$ mm (mean $16.9 \mathrm{~mm} \pm 0.4$ ); head length $\sigma: 1.0-1.4 \mathrm{~mm}$ (mean $1.2 \mathrm{~mm}$ ), $९$ : $1.1-1.3 \mathrm{~mm}$ (mean $1.2 \mathrm{~mm}$ ); pronotum length $\sigma$ : 1.4-1.7 mm (mean $1.6 \mathrm{~mm}$ ), $\%: 1.6-1.8 \mathrm{~mm}$ (mean $1.7 \mathrm{~mm}$ ); mesonotum length $\sigma: 2.6-3.2 \mathrm{~mm}$ (mean $3.1 \mathrm{~mm}$ ), $\propto: 2.9-3.4$ $\mathrm{mm}$ (mean $3.3 \mathrm{~mm}$ ); head width $\sigma^{\circ}: 3.0-3.2 \mathrm{~mm}$ (mean 3.1 $\mathrm{mm}$ ), $\$$ : 3.2-3.5 mm (mean $3.4 \mathrm{~mm}$ ); width of pronotal collar o : 3.5-4.1 mm (mean $3.9 \mathrm{~mm}$ ), : : $4.1-4.4 \mathrm{~mm}$ (mean 4.3 $\mathrm{mm})$.

Distribution (Fig. 3). - G. pallidula is only known from Jayapura (Hollandia) and surroundings in Irian Jaya, and from the Huon peninsula of Papua New Guinea.

Etymology. - Pallidula is derived from the Latin pallidus, meaning pale. The name was chosen to emphasize the close relationship of this species with G. pallida, described above. 
Guineapsaltria pennyi n. sp.

(Figs. 2, 95-110)

Material examined. - Holotype: "PAPUA NEW GUINEA: / Madang Province / Nobonob Hill / (17 km N.W. Madang), / $5^{\circ} 10^{\prime} \mathrm{S} 145^{\circ} 45^{\prime} \mathrm{E} / \mathrm{17}-18$ Feb 1987 / Norman D. Penny" (print); "Collection of the / CALIFORNIA ACADEMY / OF SCIENCES, San / Francisco, Calif." (print), $\sigma$, CAS. Paratype: Wau, Morobe Distr., 1200 m, 17.xii.1961, J. \& J.H. Sedlacek, $1 \propto$, BPBM.

Other material: British New Guinea, 1921, R. Neil, $1 \sigma$, BMNH; Boana, 1000 m, 14.iv-1.v.1965, H. Pyka, 1 o , SMN; Gang Creek Camp, Mt. Rawlinson, 4500 ft, vi.1960, seventh Archbold Exped. to New Guinea Huon peninsula, H.M. van Deusen, 1 \%, AMNH; Timbulim, Finschh., 13.x.1965, H. Pyka, $1 \propto \circ$, SMN.

Remarks. - Only males are known of this species. The material here described as $G$. pennyi is very variable and could constitute three or four separate species. The specimens share a weakly curved and sharply pointed, posteriorly directed, clasper, with large and slender, sharply edged hollow. The large clasper hollow is presumably a plesiomorphous character. The two most strongly deviating specimens, those from British New Guinea and Timbulim, are not included in the description, but discussed separately, in a note following the description.

Description. - Body of holotype olive green, of other specimens light ochraceous. Abdomen 1.2-1.4 times as long as head and thorax. Tegmen 1.2-1.3 times as long as body length.

Head: Ochraceous brown. Postclypeus smoothly rounded anteriorly, anterior margin broadly convex, continuous, or nearly continuous, with anterior margins of vertex lobes. Postclypeus distinctly swollen, anterior margin (lateral view) strongly convex in holotype, weakly convex in paratype, and almost straight in Mt. Rawlinson specimen. Lateral sides of postclypeus very smooth, with about 6 shallow furrows, in type specimens with smoothly inflated crest along lorum, in Mt. Rawlinson specimen with about 6 rows of short parallel ridges on a narrow and hardly inflated, band along lorum.

Tegmina: With distinct hyaline border along hind margin.

Tymbal organ: Five parallel sclerotized ridges spanning the tymbal from dorsal to ventral margin, a sixth ridge almost reaching ventral margin and a seventh, most proximal, ridge reaching to half the tymbal width. Six short and well-developed intercalary ridges. The Mt. Rawlinson specimen has one complete ridge less.

Opercula: Male operculum (Fig. 97) with distal part shorter than basal part and oblong-shaped. Lateral margin in holotype convex and almost forming a right angle with crest of basal part, in both other specimens straight and more gradually rising from that crest. Distal margin weakly convex, but straight in Mt. Rawlinson specimen. Distolateral corner rounded. Distomedial corner rectangular. Medial margin straight. Operculum of Mt. Rawlinson specimen distinctly longer medially, longer than basal part, with long, angularly bent medial margin (Fig. 96). Gap between operculum and abdomen very wide; operculum not covering tymbal cavity in ventral view; folded membrane clearly visible. Meracanthus not reaching abdomen.

Abdomen: Uniformly ochraceous or greenish, sometimes with reddish segmental hind margins. First tergite very short, but not hidden under metanotum medially.

Male genitalia: Pygofer in lateral view as in Fig. 98. Dorsal margin straight, angularly bent into stout and strongly convex caudodorsal beak. Distal margin weakly convex, making an obtuse angle

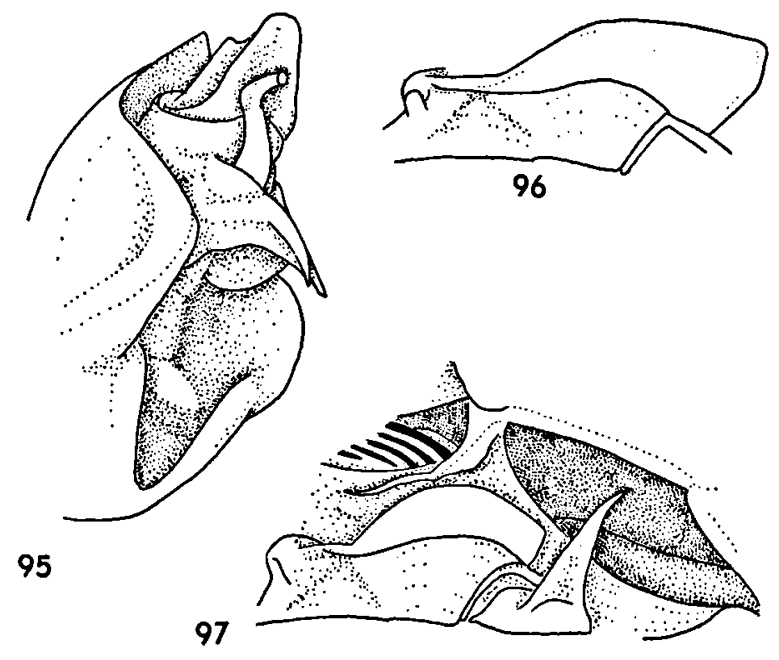

Figs. 95-97. Guineapsaltria pennyi n. sp.: 95, pygofer from aslant, holotype; 96, male operculum, Mt. Rawlinson; 97, id., holotype. 


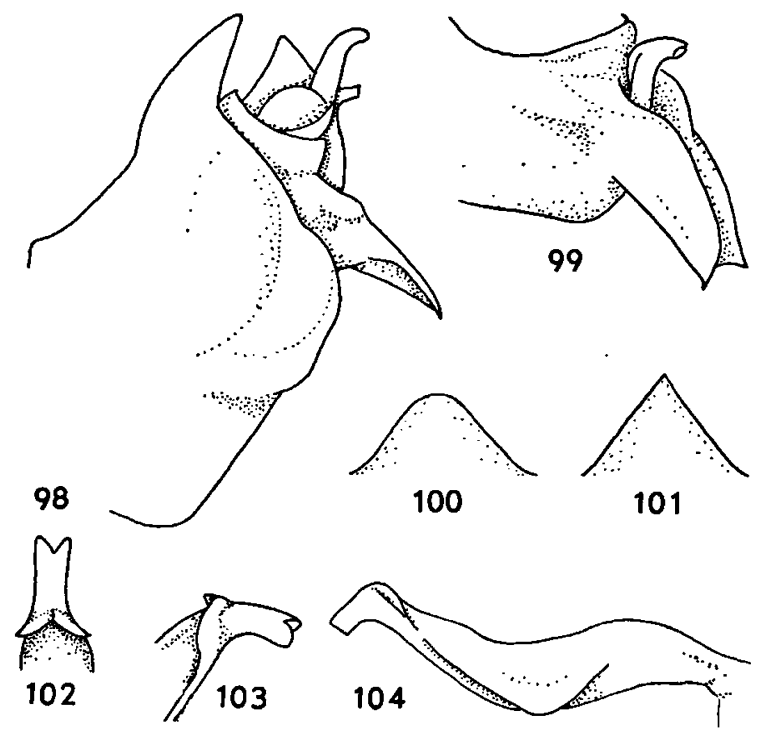

Figs. 98-104. Guineapsaltria pennyi n. sp.: 98, pygofer in lateral view, holotype; 99 , claspers, Boana; 100 , male caudodorsal beak in dorsal view, Mt. Rawlinson; 101, idem, holotype; 102, apex of aedeagus from above, Wau; 103, detail apex of aedeagus, Wau; 104, aedeagus in lateral view, Wau.

with straight margin of beak. Ventral margin straight. Lateral lobe of pygofer almost globularly rounded, sharply curving inwards towards distal margin, but recurving near distal margin and sharply curving outwards towards ventral margin, forming an oblong-shaped laminiform lateral protuberance. This protuberance is distinctly smaller and more swollen in the Mt. Rawlinson specimen. Pygofer weakly incurving towards ventral margin. Ventral margins converging, forming a sharp angle at base of pygofer opening (Fig. 95). Caudodorsal beak in dorsal view (Fig. 101) triangle-shaped and pointed at apex, but rounded in the Mt. Rawlinson specimen (Fig. 100). Claspers, parallel and directed posteriad, sharply pointed at apex (Fig. 99). Apical part of clasper with large, sharply edged clasper hollow. Dorsal parts of claspers not fused; aedeagus erect and passing between proximal parts of claspers, adjacent to anal valves. Clasper base in holotype and specimen from Boana forming a broad and smoothly rounded collar around base of anal valves (as in $G$. chinai), this collar being less distinct in other material. Clasper of Mt. Rawlin- son specimen shorter, broader and more rounded towards apex, than in other material. Aedeagus (Fig. 104) sharply upcurved at half-length, but almost rectangularly bent down near apex, with broad, and rounded lateral crests and weakly developed ventral crest, the latter most prominent in the Mt. Rawlinson specimen. The lateral crests bend upwards at distal ends and fuse to a slender, and medially incised collar around apical bending point of aedeagus. Apex of aedeagus sharply incised, ending in two apical lobes (Figs. 102-103).

Measurements. - Body length: $16.1-17.2 \mathrm{~mm}$; tegmen length: 20.4-21.5 mm; head length: 1.2-1.6 mm; pronotum length: 1.9-2.0 mm; mesonotum length: $3.7-3.9 \mathrm{~mm}$; head width: $3.4-3.8 \mathrm{~mm}$; width of pronotal collar: $4.9-5.1 \mathrm{~mm}$.

Distribution (Fig. 3). - Northeast Papua New Guinea, on and near the Huon peninsula.

Note. - The specimen from Timbulim is much smaller than the other material (body length: 12.7

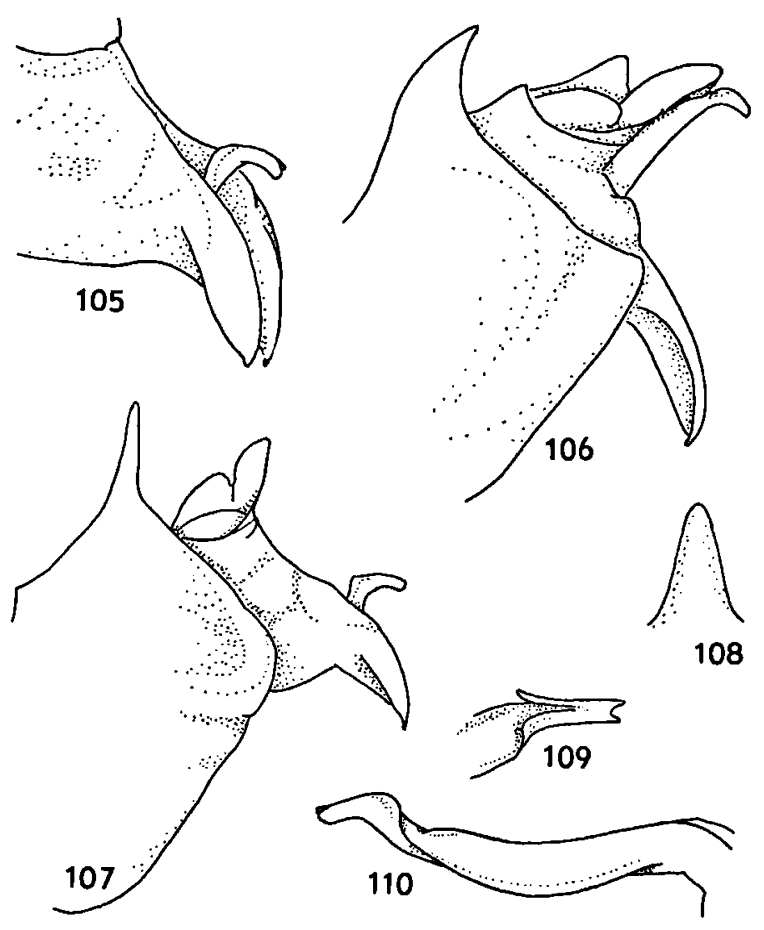

Figs. 105-110. Guineapsaltria pennyi n. sp.: 105, claspers, British New Guinea; 106, pygofer in lateral view, Timbulum; 107, id., British New Guinea; 108, male caudodorsal beak in dorsal view, British New Guinea; 109, detail apex of aedeagus, British New Guinea; 110, aedeagus in lateral view, British New Guinea. 
$\mathrm{mm})$. The specimen has extremely long and slender claspers, and is conspicuous by the strongly outwards folding lateral lobe of the pygofer, which does not bear a swollen protrusion (Fig. 106).

The specimen from British New Guinea shares very similarly curved and pointed claspers with the other specimens of $G$. pennyi and is presumably closely related to that species. However, the aedeagus passes between the claspers at about half of their length, as in G. pallida and G. pallidula, while the proximal parts of the claspers are fused as in $G$. flava, G. flaveola, and G. stylata (Figs. 105-107). The specimen has a fairly straight aedeagus (Fig. 110), with paired subapical lobes as in G. pallida and G. pallidula (Fig. 109) and a very slender and upcurving caudodorsal beak (Figs. 107, 108).

Etymology: The species is named in honour of $\mathrm{Mr}$. Norman D. Penny, who collected the holotype and many other specimens of New Guinean cicadas on which the current revision of the "Baeturia and related genera complex" is based.

\section{Acknowledgments}

For the loan of material I am indebted to: Dr. R.T. Schuh (AMNH); Mr. B.J. Day and Mr. M.S. Moulds (AMS); Dr. W.J. Knight and Mr. M.D. Webb (BMNH); Mr. G.M. Nishida (BPBM); Dr. P.H. Arnaud (CAS); Dr. B.P. Moore (CSIRO); Dr. V. Raineri (MSNG); Dr. M. Amir (MZB); Dr. L.L. Deitz (NCSU); Mr. J. van Tol (RMNH); Mr. F. Heller (SMN); Dr. T. Vásárhelyi (TMB); the staff of the National Museum and Art Gallery of Papua New Guinea (UPNG); and Dr. U. GöllnerSchneiding and Dr. J. Deckert (ZMB). Mr. M.S. Moulds kindly donated specimens from his private collection.

I would like to thank Mr. G. Verlaan for technical assistance and Mr. D.A. Langerak for drawing the maps (Figs. 1-3). I am indebted to Dr. J.P. Duffels and Prof. Dr. F. Schram (Instituut voor Taxonomische Zoölogie, Amsterdam) for their critical reading and comments on the manuscript.

\section{References}

Anonymous, 1938. Atlas van tropisch Nederland: [i-ix], maps 1-31b, legenda 1-31b, 1-17 (Koninklijk Nederlands Aardrijkskundig Genootschap \& Topografische Dienst in Nederlandsch-Indië, Amsterdam/Batavia).
Anonymous, 1966. List of New Guinea localities: 1-19 (Bernice P. Bishop Museum, Honolulu).

Anonymous, 1968. The Times atlas of the world: i-xliii, 1-272, pls. 1-123 (Times Newspapers Ltd., London).

Blöte, H.C. 1958. On the history of the genus Baeturia Stål (Insecta, Homoptera, Cicadidae). Archs. néerl. Zool., 13 (Suppl. 1): 262-269.

Blöte, H.C., 1960. The genus Baeturia Stál as represented in New Guinea (Homoptera, Cicadidae). Zoöl. Meded. Leiden, 37: 61-80.

Boer, A.J. de, 1982. The taxonomy and biogeography of the nasuta group of the genus Baeturia Stål, 1866 (Homoptera, Tibicinidae). Beaufortia, 32 (4): 57-78.

Boer, A.J. de, 1990. Aedeastria, a new cicada genus from New Guinea, its phylogeny and biogeography (Homoptera, Tibicinidae), preceded by a discussion on the taxonomy of New Guinean Tibicinidae. Beaufortia, 40 (3): 63-72.

Boer, A.J. de, 1991. Scottotympana, a new cicad genus from New Guinea, with the description of three new species, their taxonomy and biogeography (Homoptera, Tibicinidae). Beaufortia, 42 (1): 1-11.

Boer, A.J. de, 1992. The taxonomy and biogeography of the genus Thaumastopsaltria Kirkaldy, 1900 (Homoptera, Tibicinidae). Beaufortia, 43 (3): 17-44.

Burns, A.N., 1957. Checklist of Australian Cicadidae. Ent. Arb. Mus. Georg Frey, 8 (2): 609-678.

Distant, W.L., 1906. A synonymic catalogue of Homoptera. Part 1. Cicadidae: 1-207 (Trustees Indian Museum, London).

Distant, W.L., 1907. Rhynchotal notes. XLIII. Ann. Mag. nat. Hist., (7) 20: 411-423.

Duffels, J.P., 1977. A revision of the genus Diceropyga Stål, 1870 (Homoptera, Cicadidae). Monografieën ned. ent. Veren., 8: 1-227.

Duffels, J.P. \& P.A. van der Laan, 1985. Catalogue of the Cicadoidea (Homoptera, Auchenorhyncha) 1956-1980. Series Ent., 33: i-xvi, 1-414.

Goding, F.W. \& W.W. Froggatt, 1904. Monograph of the Australian Cicadidae. Proc. Linn. Soc. N.S. Wales, 29: 561 668.

Kirkaldy, G.W. 1907. Some annotations to M. Distant's recent Catalogue of the Cicadidae (Hem.). Annis. Soc. ent. Belg., 51: 303-309.

Metcalf, Z.P., 1963. General catalogue of the Homoptera, VIII. Part 2. Tibicinidae: i-iv, 1-492 (North Carolina State College, Raleigh, N.C.).

Moulds, M.S., 1990. Australian cicadas: 1-217 (New South Wales University Press, Kensington).

Myers, J.G., 1928. Cicadidae. In: Insects of Samoa and other Samoan terrestrial Arthropoda, 2 (2): 55-65 (Trustees of the British Museum, London).

Wheeler, T., 1988. Papua New Guinea a travel survival kit: 1-340 (Lonely Planet Publications, Victoria, Australia).

Received: 10 September 1992

Revised: 5 February 1993 